\title{
Extreme daily rainfall in Pakistan and north India: scale-interactions, mechanisms, and precursors
}

Article

Accepted Version

Hunt, K. M. R., Turner, A. G. and Shaffrey, L. C. (2018) Extreme daily rainfall in Pakistan and north India: scaleinteractions, mechanisms, and precursors. Monthly Weather Review, 146 (4). pp. 1005-1022. ISSN 0027-0644 doi: https://doi.org/10.1175/MWR-D-17-0258.1 Available at https://centaur.reading.ac.uk/75584/

It is advisable to refer to the publisher's version if you intend to cite from the work. See Guidance on citing.

To link to this article DOI: http://dx.doi.org/10.1175/MWR-D-17-0258.1

Publisher: American Meteorological Society

All outputs in CentAUR are protected by Intellectual Property Rights law, including copyright law. Copyright and IPR is retained by the creators or other copyright holders. Terms and conditions for use of this material are defined in the End User Agreement.

www.reading.ac.uk/centaur 
Central Archive at the University of Reading

Reading's research outputs online 


\title{
Extreme daily rainfall in Pakistan and north India: scale-interactions, mechanisms, and precursors
}

\author{
KIERAN M. R. HUNT* \\ Department of Meteorology, University of Reading, Reading, United Kingdom. \\ ANDREW G. TURNER \\ NCAS, University of Reading, United Kingdom; and Department of Meteorology, University of Reading, United \\ Kingdom. \\ LEN C. SHAFFREY \\ NCAS, University of Reading, United Kingdom
}

\begin{abstract}
While much of India is used to heavy precipitation and frequent low-pressure systems during the summer monsoon, towards the northwest and into Pakistan, such events are uncommon. Here, as much as a third of the annual rainfall is delivered sporadically during the winter monsoon by western disturbances. Such events of sparse but heavy precipitation in this region of typically mountainous valleys in the north and desert in the south can be catastrophic, as in the case of the Pakistan floods of July 2010. In this study, we identify extreme precipitation events (EPEs) in a box approximately covering this region $\left(65^{\circ}-78^{\circ} \mathrm{W}, 25^{\circ}-38^{\circ} \mathrm{N}\right)$ using the APHRODITE gauge-based precipitation product. The role of the large-scale circulation in causing EPEs is investigated: it is found that, during winter, they often coexist with an upper-tropospheric Rossby wave train that has prominent anomalous southerlies over the region of interest. These winter EPEs are also found to be strongly colocated with incident western disturbances whereas those occurring during the summer are found to have a less direct relationship. Conversely, summer EPEs are found to have a strong relationship with tropical lows. A detailed Lagrangian method is used to explore possible sources of moisture for such events, and suggests that in winter, the moisture is mostly drawn from the Arabian Sea, whereas during the summer, it comes from along the African coast and the Indian monsoon trough region.
\end{abstract}

\section{Introduction}

The catastrophic floods in Pakistan at the end of July 2010 exemplified the risks of heavy rainfall falling over a cascading mountainous region upstream of desertic plains with typically low hydrological fluxes. This special case was preempted by a significant drought in the summer of 2009, followed by large-scale atmospheric features throughout July 2010; in fact, some forecasts predicted the intensity and scale as much as a week in advance (Webster et al., 2011). While the July 2010 floods were a freak incident, this region - Pakistan and Northwest India - has been shown to be highly susceptible to heavy rainfall on large, coherent spatial scales during the ISM (Malik et al., 2012), as shown in Tab. 1; this is made all the more critical by recent work showing that both mean rainfall and frequency of extremes in this area are predicted to increase under likely future climate scenarios (Palazzi et al., 2013,

\footnotetext{
${ }^{*}$ Corresponding author address: Kieran M. R. Hunt, Department of Meteorology, University of Reading, Reading, UK.

E-mail: k.m.r.hunt@ reading.ac.uk
}

2015). Rasmussen et al. (2015) looked at three recent anomalous flooding events in Pakistan, identifying the importance of mesoscale convective systems in the region, and noting the existence of a quasistationary Rossby wave train aloft in all three cases - agreeing with the findings of Lau and Kim (2012) for the July 2010 floods. Martius et al. (2013) showed that a significant factor in the July 2010 floods was a combination of anomalous boundary layer southerlies bringing moisture from the Arabian Sea combined with upper-level westerly PV anomalies.

These are only case studies, however, and we must ask whether these large-scale features are typically present during general cases of anomalously heavy precipitation in this region; and, from where does this anomalous moisture originate?

One approach is to look at whether there are local synoptic systems bringing moisture over the region of interest. There are two types of rain-bearing systems that impact north India and the surrounding region: upper-level western disturbances (e.g. Dimri et al., 2015) and cyclone- 


\begin{tabular}{|r|c|c|}
\hline Date & Area & Fatalities \\
\hline \hline Jul 2003 & SE Pakistan & 484 \\
\hline Jul-Aug 2007 & Pakistan & 967 \\
\hline Jul 2010 & Pakistan, especially N & 1781 \\
\hline Aug 2010 & N India & 255 \\
\hline Sep 2011 & SE Pakistan & 361 \\
\hline Sep 2012 & N Pakistan & 100 \\
\hline Jun 2013 & N India & 5748 \\
\hline Aug 2013 & N Pakistan, Afghanistan & 80 \\
\hline Sep 2014 & N India & 557 \\
\hline
\end{tabular}

TABLE 1. Dates, locations, and minimum fatalities of selected floods in Pakistan and north India. [Source: selected news outlets]

like tropical monsoon lows (e.g. Hurley and Boos, 2015). Climatologies and catalogues of each have been produced by the author (Hunt et al., 2016a, 2017) as well as others (Sikka, 2006; Hurley and Boos, 2015) and are thus easily interrogated.

In this study, we will explore the mechanisms behind heavy precipitation in the northwest subcontinent. We will develop a catalogue of such events using gauge-based data, using it to probe the relationship with local synopticscale circulations, and local as well as more distant forcings. We will also look at the sources of moisture through analysis of local moisture-flux fields and parcel-tracking.

We start with an overview of the data sources (Sec. 2a), before outlining the methods of selection for the domain (Sec. 2b1), identifying extreme precipitation events (Sec. 2b2) and Lagrangian parcel tracking (Sec. 2b3). Then, in Sec. 3, we look at the effect of the large scale circulation (Sec. 3a), the effect of local synoptic systems (Sec. 3b). Finally, we investigate the source of the moisture involved through Eulerian and Lagrangian analysis (Sec. 4), then concluding in Sec. 5.

\section{Data and methods}

\section{a. Data}

\section{1) APHRODITE}

The Asian Precipitation - Highly-Resolved Observational Data Integration Towards Evaluation of Water Sources (APHRODITE; Yatagai et al., 2009, 2012) is a daily, gridded, gauge-based product available over monsoon Asia with resolution of $0.25^{\circ}$. It covers the period 1951-2007, and is one of best gauge products available over India in terms of continuity, gauge density, and longevity (Prakash et al., 2015). Unfortunately the gauge density reaches a minimum over India in our areas of interest due to the mountainous terrain, namely the Karakoram and Hindu-Kush regions. Still, in using gauge data, APHRODITE performs well when compared to satelliteonly and blended precipitation products (Guo et al., 2015).

\section{2) ERA-INTERIM}

The European Centre for Medium-Range Weather Forecasting (ECMWF) re-analysis interim project (ERAInterim; Dee et al., 2011) is a six-hourly, global dataset with approximate resolution of $0.7^{\circ}$. A large number of variables are available over 37 pressure levels from $1000 \mathrm{hPa}$ to $0.1 \mathrm{hPa}$, with 27 of these levels nominally in the troposphere (below $100 \mathrm{hPa}$ ). It spans 1979 to the present, and assimilates external data from a variety of sources, including rawinsondes, buoys, and satellites.

\section{b. Methodology}

\section{1) Selection of DOMAIN}

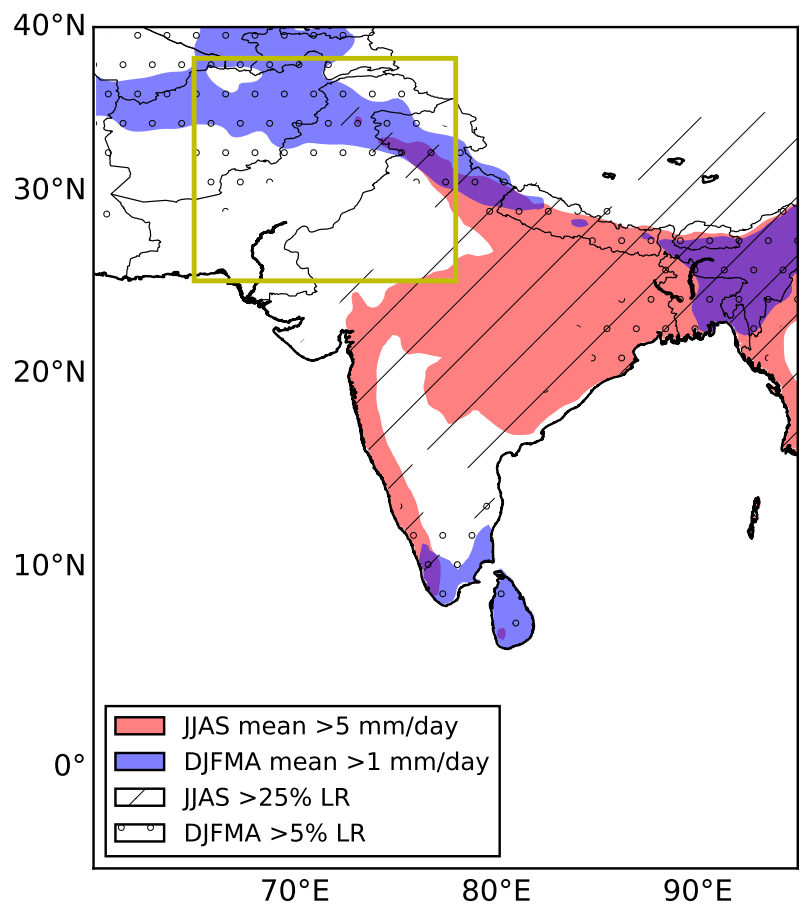

FIG. 1. Some rainfall metrics over the subcontinent and surrounding area, computed using APHRODITE. Areas where the mean summer (Jun-Sep) rainfall exceeds $5 \mathrm{~mm} \mathrm{day}^{-1}$ are coloured in red; those where the mean winter (Dec-Apr) rainfall exceeds $1 \mathrm{~mm} \mathrm{day}^{-1}$ are coloured blue. Hashing indicates areas where at least a quarter of summer days have light rainfall ( $>2.5 \mathrm{~mm} \mathrm{day}^{-1}$, as defined by the IMD), and stippling where at least a twentieth of winter days meet the same criterion. Note that here and throughout, borders are purely illustrative, and do not represent the authors' political affiliations.

An informed domain selection is vital, particularly as the tail of the rainfall distribution is likely to be highly sensitive to it. Here, we seek a domain that is large enough to capture the mountainous and dry regions of northwest India and Pakistan that are of interest, but not so large that it starts to encompass regions with significantly different climate/precipitation regimes. We can attack this problem 
using gauge data from APHRODITE: Fig. 1 shows selected rainfall statistics for the region of interest. The red area denotes where the mean summer (June - September) precipitation exceeds $5 \mathrm{~mm}$ day $^{-1}$, the blue area where mean winter (December - April) precipitation exceeds 1 $\mathrm{mm}$ day $^{-1}$, hashing indicates where at least a quarter of summer days receive a minimum of $2.5 \mathrm{~mm} \mathrm{day}^{-1}$, and stippling where this is the case for $5 \%$ of winter days. There is a marked area of very low precipitation in both seasons in northwest India and south Pakistan, north of which are the foothills of the Karakoram and Hindu Kush (see Fig. 2). Case studies of previous floods in this region have shown that both heavy rainfall over the mountains in the north (cascading downstream and flooding the rivers towards the south) and anomalously heavy rainfall in the south (from, e.g. cyclones) can be responsible (e.g. Sayama et al., 2012; Rasmussen and Houze, 2012; Martius et al., 2013; Houze et al., 2017). As such, our domain should include both areas, whilst not extending too far towards the summer monsoon core zone. To this end, and using some additional cluster analysis which is not shown here, we selected the box bounded by $65-78^{\circ} \mathrm{W}, 25-38^{\circ} \mathrm{N}$ as our domain of interest. Hereafter we shall refer to this region as Hindustan; this box is shown as the yellow rectangle in both Figs. 1 and 2.

\section{2) Selection of extreme events}

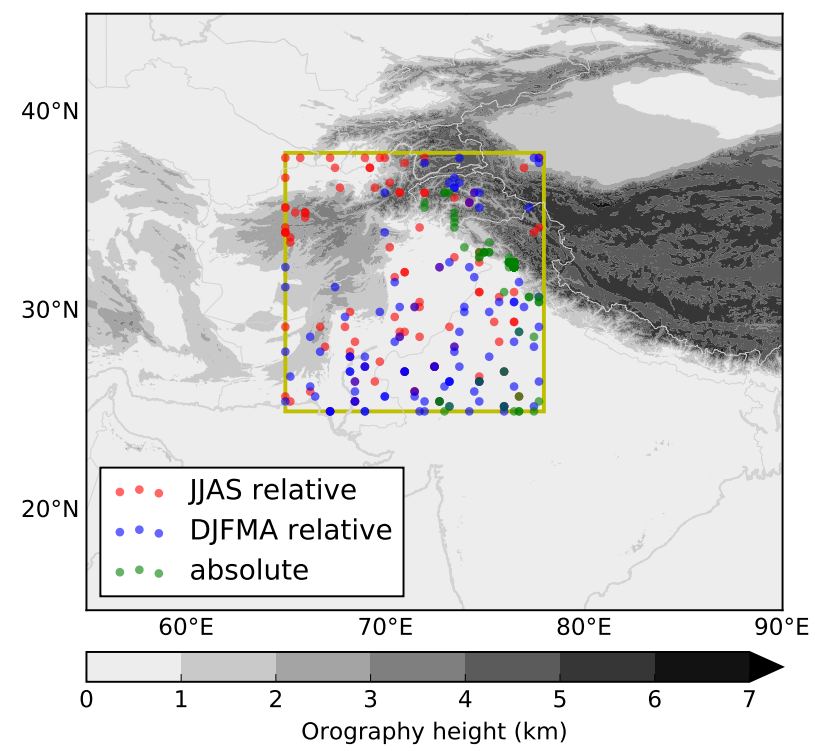

FIG. 2. Illustration of the Hindustan domain (yellow box, as given in Fig. 1), with the locations of the hundred strongest absolute EPEs across all seasons (green), and the hundred relative strongest for JuneSeptember (red) and December-April (blue). EPEs computed using APHRODITE data. Grayscale contours represent orography.

There are two simple ways in which we can look for extreme precipitation events (hereafter EPES), both of which are common in previous studies on flooding. Firstly, we could simply siphon off the top $n$ values from the raw distribution, this would give us the $n$ strongest absolute EPEs; these typically occur along the foothills of the Karakoram, towards the northeast of the Hindustan box.

These absolute events are of some interest (green dots in Fig. 2), typically in the foothills of the Karakoram in the north, they can trigger local landslides, as well as creating potentially catastrophic runoff, causing flooding downstream. Even so, and perhaps somewhat counterintuitively, these events do not tend to be anomalously high - they typically occur in regions where the mean precipitation is already very substantial, and thus constitute only a small addition to say, an average seasonal high. Secondly, we could look at the distribution of standardised precipitation indices, the more common practice in flooding analyses. Normalising the data (on a per pixel basis) by its seasonal mean and standard deviation ensures that those values at the top are indeed locally devastating, and thus within our remit. Hereafter these will be referred to as relative EPEs, the top hundred ${ }^{1}$ of which are given for summer and winter by the red and blue markers respectively in Fig. 2. Since we are using daily data for this, we cannot know what time in the day the EPE happens. Therefore, all composites and statistics that would require such information in this study are conducted as though the EPE occurs at $12 \mathrm{Z}$.

We note that despite the pixel-based selection process, these storms have some spatial extent: approximately $100 \mathrm{~km}$ and $40 \mathrm{~km}$ radius to half-intensity for relative and absolute EPEs respectively. The value of the former, which does not differ significantly between seasons, is similar to the precipitation footprint sizes for synoptic systems that impact this region (Hunt et al., 2016b, 2017).

\section{3) LAGRANGIAN PARCEL TRACKING}

In order to identify possible sources of moisture associated with an EPE, one can decompose the column of atmosphere directly above it into a given number of points, then treating those points as infinitesimal parcels, advect them backwards using reanalysis wind data. The prescription is generally simple, and is outlined here:

1. Identify the start date, time, and location of interest, here selected from heavy precipitation events. Find the three-dimensional wind vector at this point.

\footnotetext{
${ }^{1}$ A small caveat here: as precipitation has a moderate spatial autocorrelation, some of these events happen near each other and on the same, or consecutive, days; where this is the case, the highest SPI event has been taken forward, and the others - subject to a two day window - rejected. We then look for the next highest SPI on other days and continue until the population is 100 .
} 
2. Having predetermined the integration time from sensitivity tests ${ }^{2}$, advect the parcel backward, e.g. by changing the signs of the components of the wind vector, using the spherical equations defined in the Appendix.

3. Given that most reanalyses do not have unlimited resolution, the resulting point will not be at a coordinate that one has exact data for in either space or time. Therefore, we recompute the local reanalysis field for the correct time using a cubic spline, and then use a tricubic method (Lekien and Marsden, 2005) on this field to estimate the wind vector at the required location.

4. Return to (1) using the new time, location, and winds; repeat for the duration of the integration.

Qualitatively, this is essentially the same as running the passive tracer component of NOAA's HYSPLIT model without the turbulent dispersion correction. Evaluation of a selection of case studies (not shown) indicates that results from the two methods are quantitatively very similar.

We are interested in a region known for its variable and steep orography, as a result, and even when using short integration times, some parcels can end up being advected below the local surface. In such cases, which are trivially small in number, the trajectory is rejected from further analysis.

\section{Results}

\section{a. Large-scale features}

The first important step that one can take when diagnosing the mechanisms behind a particular type of event is to look at the mean state of some fields in the large scale. This serves to alert us to the types and locations of precursors that exist, if any. To ensure that our conclusions are robust, we must next take two steps: firstly, we must consider only the perturbations to the mean - for this we subtract the daily climatology; and secondly we must separate the analysis by season due to the strong seasonality inherent in the South Asian monsoon region. In the case of the former, we avoid deductions such as "the jet is responsible because it is in the composite" when it is in fact perhaps an omnipresent background feature anyway. For the latter, it is a case of not conflating two distinct patterns and thence making an incorrect assumption; for example, the subtropical westerly jet is in significantly different locations over the Eurasian continent during summer as opposed to during winter, whereas its intraseasonal variability is comparably low (Schiemann et al., 2009).

\footnotetext{
${ }^{2}$ We use an integration time of twenty minutes, as returns on accuracy drastically diminish beyond this.
}

\section{1) BOREAL SUMMER}

Bearing the above discussion in mind, Fig. 3 shows the composite large-scale features present in selected variables during the 100 events with the highest standardised precipitation index in June-September (the hundred strongest relative EPEs), all presented as anomalies to the daily climatology. The first panel, Fig. 3(a), shows the composite mean 450-200 hPa meridional wind speed anomaly. The most prominent signal is the presence of southerlies over north Pakistan; these are part of a weak, but nonetheless spatially coherent wavelike signal reaching from northeast Europe to Japan. This upper-level wind pattern bears a strong resemblance to that found for previous composites and case studies of floods in this region (Houze et al., 2011; Rasmussen and Houze, 2012; Rasmussen et al., 2015).

A similar, but appropriately orthogonal pattern is seen in Fig. 3(b) for geopotential: a wavelike feature extends to the west, with a minimum situated over Afghanistan. Towards the east, the zonal pattern breaks up and becomes distinctly meridional, presumably due to the significant effects the summer heating of the Tibetan Plateau has on the surrounding atmosphere (Boos and Kuang, 2010). This can be seen as a northward extension of the upper-level summer Tibetan high (e.g. Krishnamurti et al., 2008).

Fig. 3(c) shows the total column water anomaly composite. As one might expect, there is a significant positive anomaly over Pakistan and northwest India; this can be viewed as a northwestward extension of the summer monsoon bringing plentiful moisture to a typically arid region. Combining this with the anomalous southerlies (not shown; although they are weaker at lower levels than in Fig. 3(a), they are still notable) and complex orography in the region, one could conclude that the precipitation happening here is in part orographically-driven, as has been shown before (e.g. Romatschke et al., 2010; Romatschke and Houze, 2011).

Finally, lower-tropospheric (900-800 hPa) temperature is given in Fig. 3(d); this has been shown to be a good proxy for moist thermodynamic activity in tropical synoptic systems (e.g. Hunt et al., 2016b, 2017). The cold anomaly covers a large area of Pakistan and surrounding countries, reaching a magnitude of $-2 \mathrm{~K}$ at the centre. Given the pronounced colocation of this with the total column water anomaly, it is probable that this deep cold anomaly is a result of heavy precipitation. On the other (east) side of the Tibetan Plateau, a contrasting warm anomaly is found, where the atmosphere is dry, and some descent is present.

\section{2) BOREAL WINTER}

Having looked at the synoptic situation for extreme precipitation during summer, we now repeat the analysis for 


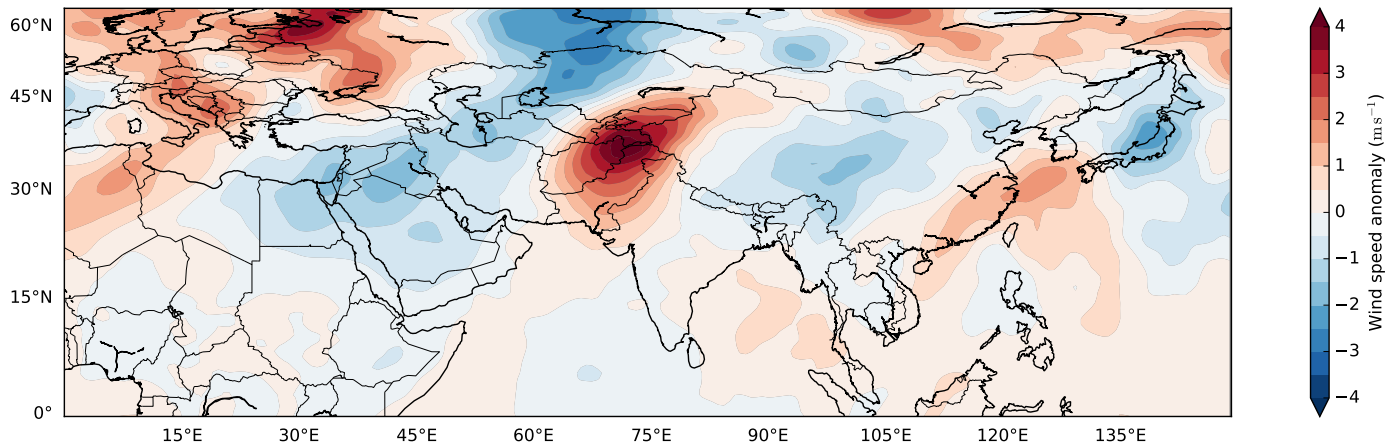

(a) Meridional wind speed anomaly $(450-200 \mathrm{hPa})$

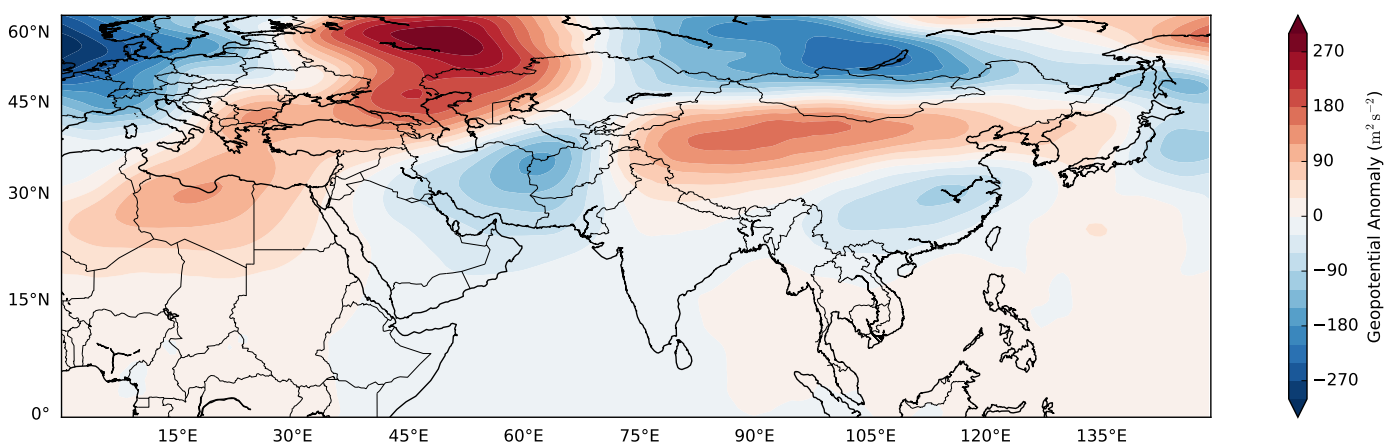

(b) Geopotential anomaly $(450-200 \mathrm{hPa})$

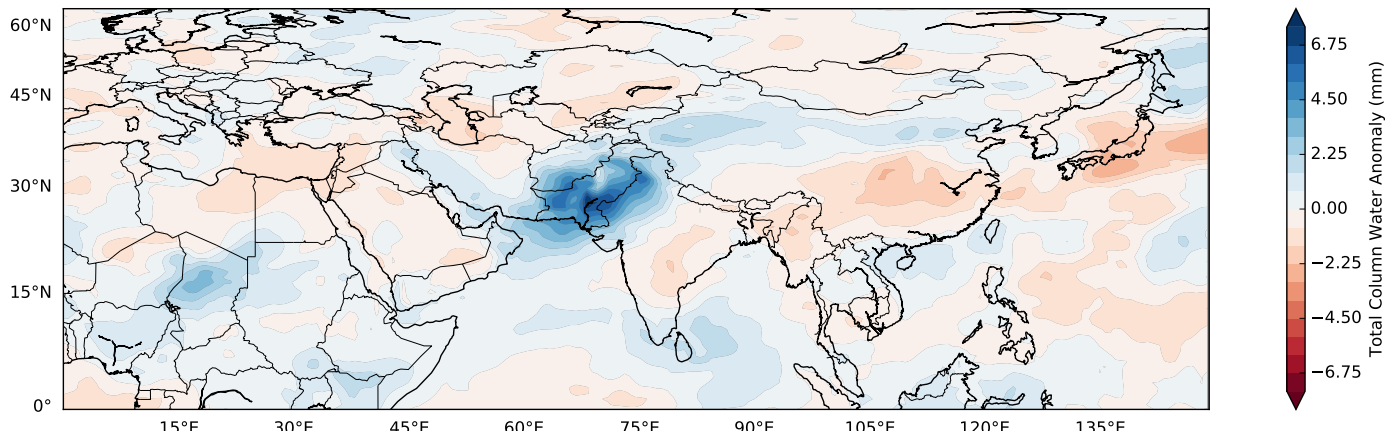

(c) Total column water anomaly

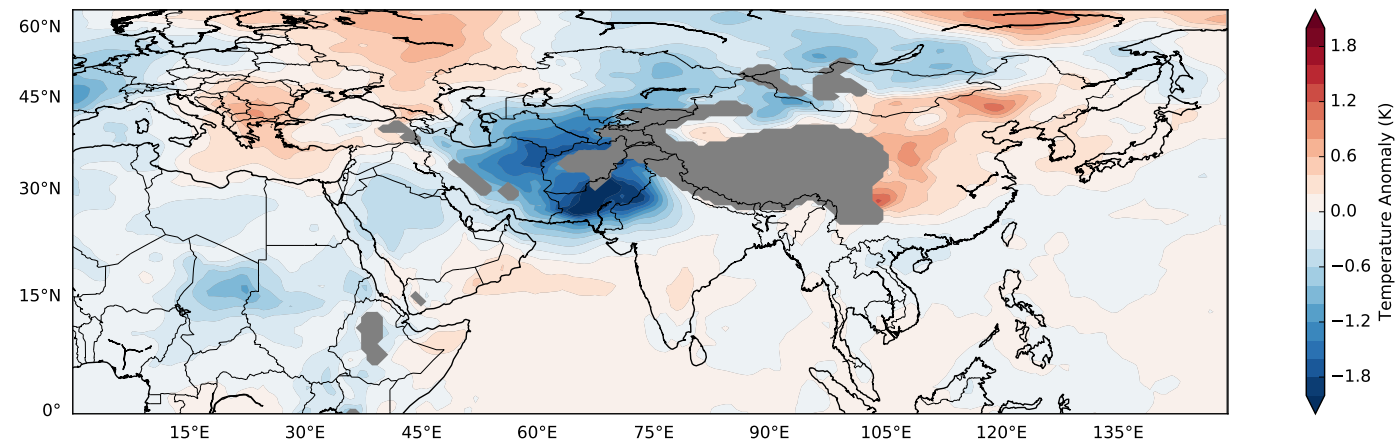

(d) Temperature anomaly $(900-800 \mathrm{hPa})$

FIG. 3. Mean large-scale features in selected fields during the 100 strongest relative EPEs for June-September in the Hindustan region in APHRODITE, i.e. the hundred days containing pixels with the highest standardised precipitation index. Anomalies are computed against the Julian day mean over the ERA-Interim period. Greyed out areas indicate that the pressure level of the variable is greater than the surface pressure. 
M O N T H L Y W A T H E R R E I E W

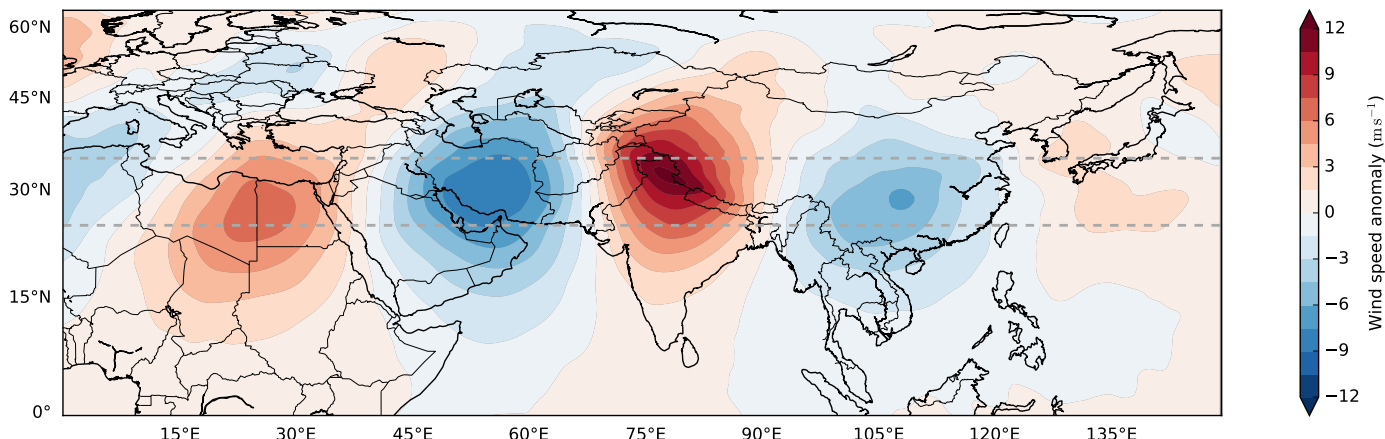

(a) Meridional wind speed anomaly (450-200 hPa)

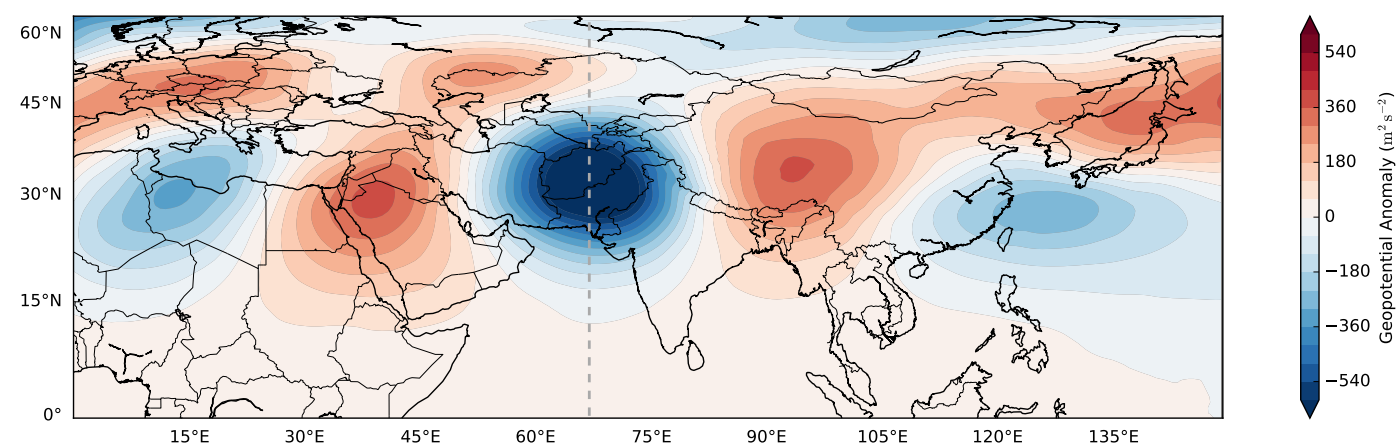

(b) Geopotential anomaly (450-200 hPa)

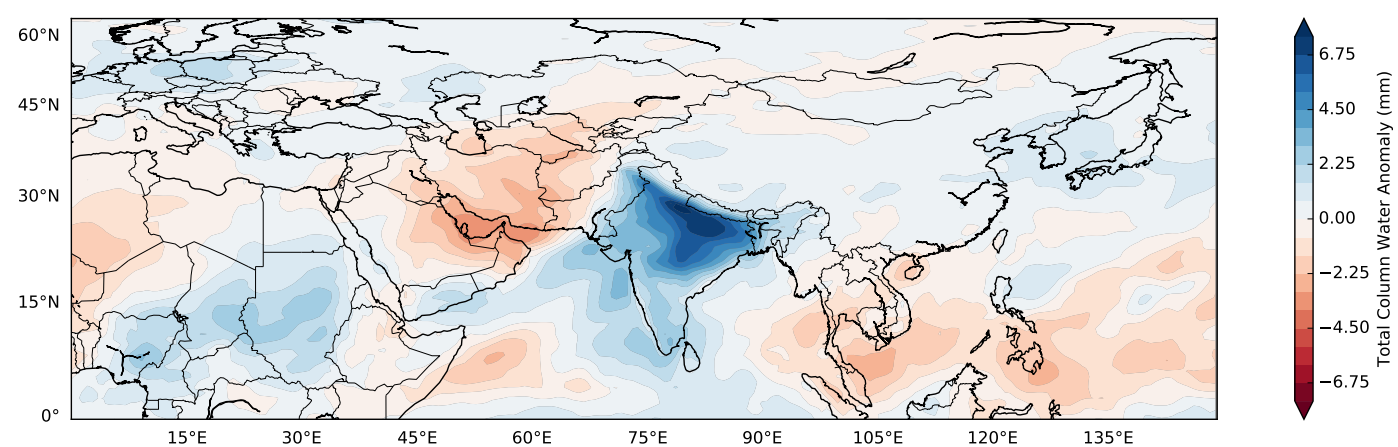

(c) Total column water anomaly

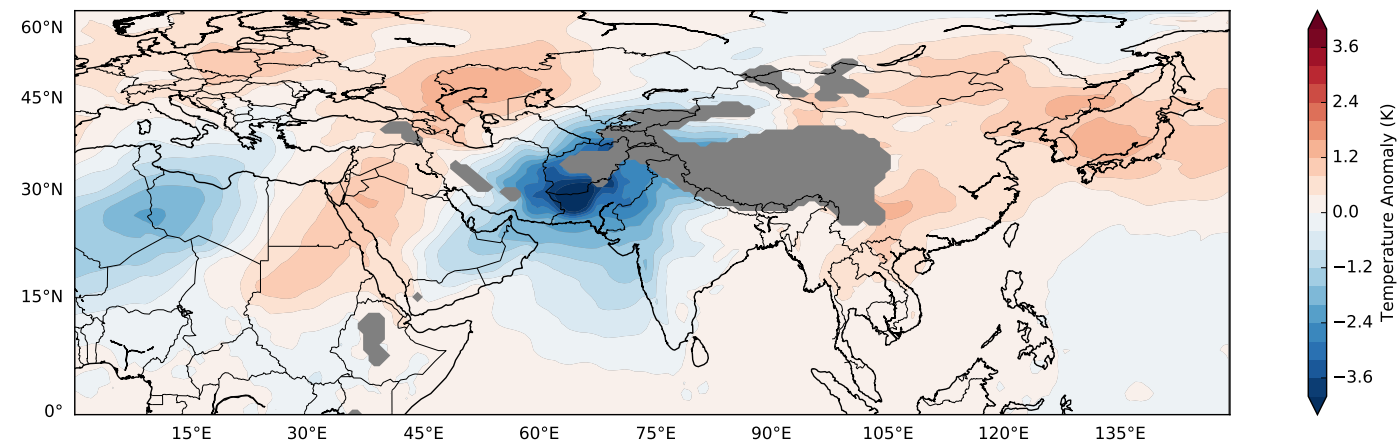

(d) Temperature anomaly $(900-800 \mathrm{hPa})$

FIG. 4. As in Fig. 3, but for December-April. Grey dashed lines on (a) indicate the 25th and 35th parallels, the bounds of the domain for which the Hovmöller diagram in Fig. 5 is computed; on (b) the grey dashed line indicates the longitude for which Fig. 6 is computed. Note that the colour scales differ from those figures. 
winter, shown in Fig. 4. The first panel shows the composite meridional wind speed anomaly at $450-200 \mathrm{hPa}$, where a very distinct wave pattern emerges. There are pronounced anomalous southerlies over north India, three times stronger than seen in summer, with comparatively weaker northerlies over central China and the Arabian Gulf. This wave train has a wavelength of approximately $5000 \mathrm{~km}$, or a planetary wavenumber of 6 , and is $\pi / 2$ out of phase with the geopotential anomaly pattern.

Shown in Fig. 4(b), the 450-200 hPa geopotential anomaly shows a significant depression over much of Pakistan and Afghanistan. This depression is similar in altitude and magnitude to that caused by a passing western disturbance (Dimri and Chevuturi, 2016; Hunt et al., 2017). Western disturbances are known to propagate through this area during the boreal winter bringing substantial precipitation.

Fig. 4(c) shows the total column water anomaly. There is a clear difference to the summer, in that the moisture anomaly maximum is situated towards northeast India, some distance away from the area of interest. A tongue of moisture does extend into northwest India and Pakistan however, so there is a positive moisture anomaly there. The lower-tropospheric southerlies required for this can also be responsible for generating some heavy rainfall in the Himalayan foothills (Dimri, 2006).

Finally, the lower-tropospheric temperature anomaly (Fig. 4(d)) bears a similar pattern to its summer equivalent. A stronger cold anomaly of nearly $-4 \mathrm{~K}$ sits over the foothills of the Hindu-Kush. As before there is a weak warm anomaly over much of central China on the eastern side of the Tibetan Plateau. The similarity of temperature (not shown) in summer and winter compared with the other fields shown suggests that these temperature anomalies are a direct result of the precipitation.

\section{3) WINTER WAVE PROPAGATION PROPERTIES}

One of the more striking outcomes from the analysis of Figs. 3 and 4 was the wavelike feature in upper-level winds during winter relative EPEs. Naturally a contemporaneous composite provides only a snapshot in time, from which we can infer very little. Fig. 5 shows a Hövmoller diagram for meridional wind speed averaged over $450-200 \mathrm{hPa}$ and $25^{\circ}-35^{\circ} \mathrm{N}$, for a range of twenty days: from ten days preceding the event to the ten following it. The wave is again clearly present in the western hemisphere in the few days surrounding the composite precipitation event. There are distinct group and phase velocities for these prominent disturbances: these are simply calculated - the phase velocity is $4.7 \pm 1.8 \mathrm{~m} \mathrm{~s}^{-1}$, and the group velocity is $38 \pm 6 \mathrm{~m} \mathrm{~s}^{-1}$. Given that this composite wave is Rossby-like, we can compare the phase and group velocities ( $c_{p}$ and $c_{g}$, respectively) with their theoretical (barotropic) equivalents:

$$
\begin{gathered}
c_{p}=u-\frac{\beta}{k^{2}+l^{2}} \\
c_{g}=u-\frac{\beta\left(l^{2}-k^{2}\right)}{\left(k^{2}+l^{2}\right)^{2}}
\end{gathered}
$$

where $k$ and $l$ are the zonal and meridional wavenumbers ${ }^{3}$ respectively, $\beta$ is the meridional gradient of the Coriolis parameter, and $u$ is the background zonal wind. We can estimate the planetary wavenumbers directly from Figs. 4(a) and 5: $k=6$ and $l=0$. Compositing the zonal wind in the same way as was done for meridional wind anomalies in Fig. 4(a) suggests a (highly variable) speed of $20-40 \mathrm{~m} \mathrm{~s}^{-1}$ with an average of around $29 \mathrm{~m} \mathrm{~s}^{-1}$, however, using this value of $u$ overestimates $c_{p}$ and $c_{g}$ each by about $7 \mathrm{~m} \mathrm{~s}^{-1}$. If, instead, we set $u=22 \mathrm{~m} \mathrm{~s}^{-1}$, we recover theoretical values of $c_{p}$ and $c_{g}$ that match observations to within a few percent. It seems likely therefore, that this is not a purely barotropic mechanism. Presence of baroclinicity can be confirmed on looking at the vertical-meridional cross-section of a dynamic field. This is shown for geopotential anomaly for the hundred relative winter EPEs used for Fig. 4 in Fig. 6, which has a marked poleward tilt through the $68^{\circ} \mathrm{E}$ maximum indicated in Fig. 4(b). One final point of note on the discussion of Fig. 5 is that there is some evidence of the wave reinforcing itself on a full rotation, as it constructively interacts with earlier remnants. This so-called quasiresonant amplification has been shown to be a possible progenitor of weather extremes (Petoukhov et al., 2013; Coumou et al., 2014).

\section{b. Relationship with synoptic-scale dynamics}

Extreme conditions at any latitude, particularly in wind or precipitation, are often attributable to particular synoptic-scale or mesoscale events. Here, we will explore whether that is also the case for heavy precipitation in north India and Pakistan. South Asia is subject to two seasonal paradigms in this respect: in the winter, this area is subject to bombardment from western disturbances (WDs) (Dimri et al., 2015); in the summer, monsoon low pressure systems (Hurley and Boos, 2015). Even though they are strongly modulated by their respective seasonal cycles, either can occur out of season, and in the latter instance, they are more correctly referred to as tropical lows or tropical depressions (TDs). Indeed the catastrophic Pakistan floods of 2010 were linked to the interaction of a western disturbance and a monsoon low (Houze et al., 2011), and the 2013 Uttarakhand flood to the interaction of a WD and a monsoon trough (Houze et al., 2017).

\footnotetext{
${ }^{3}$ These are related to planetary wavenumbers by a factor of $2 \pi /$ (circumference of axis).
} 


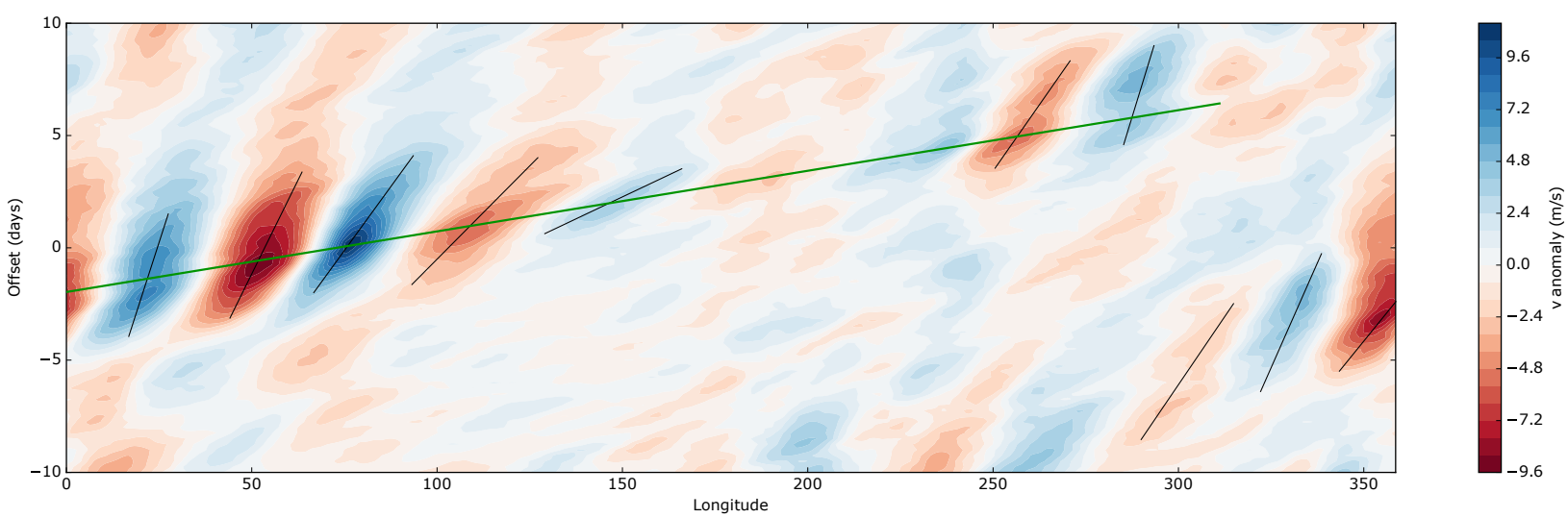

FIG. 5. Composite Hovmöller diagram for upper level meridional wind $\left(\mathrm{m} \mathrm{s}^{-1}\right)$ during extreme rainfall in December-April. $v$ is computed as a mean between $450-200 \mathrm{hPa}$ and $25^{\circ}-35^{\circ} \mathrm{N}$. Black lines indicate propagation of peaks (i.e. phase velocity), the green line indicates the propagation of the wave pattern (i.e. group velocity).

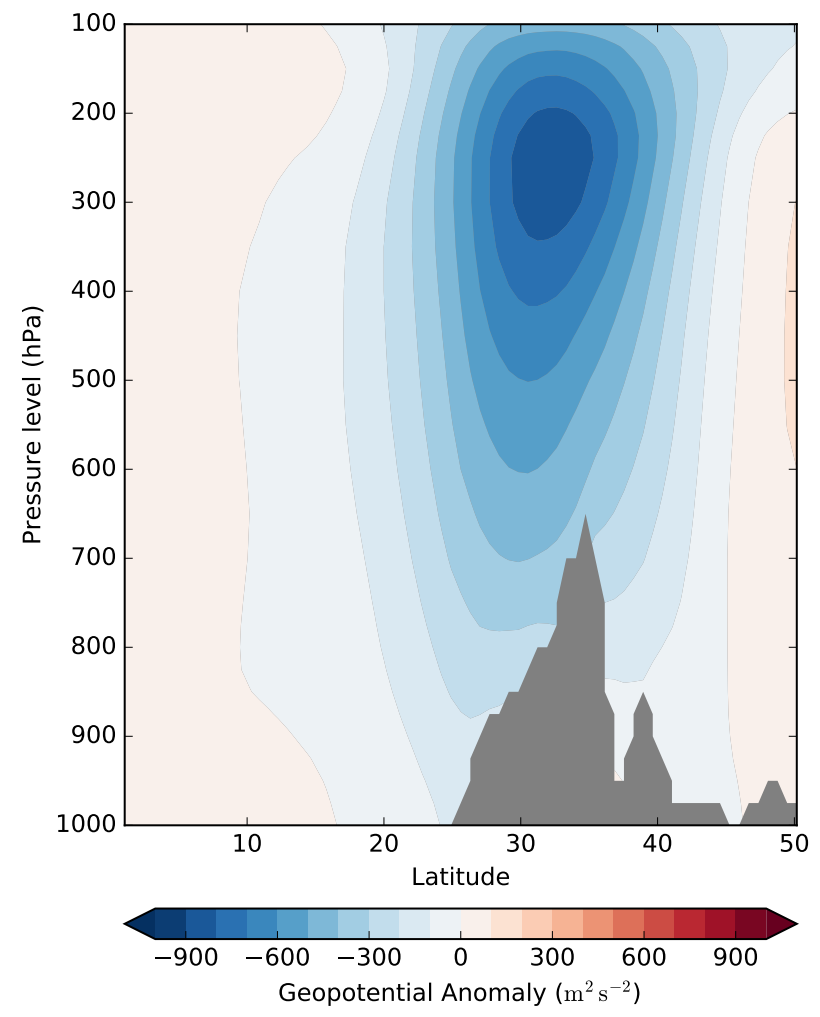

FIG. 6. Vertical structure of geopotential anomaly for the hundred strongest winter EPEs. Construction as in Fig. 4(b), with the crosssection taken along the line given in that figure $\left(68^{\circ} \mathrm{E}\right)$. Grey areas indicate the presence of orography.

Using the hundred absolute and relative strongest EPEs in the Hindustan region (see Sec. 2), we can find the locations of the nearest synoptic-scale systems from exist- ing databases (Hunt et al., 2016a, 2017) ${ }^{4}$. APHRODITE data were used as previously, where the period intersected that of ERA-Interim (1979-2007), to determine the locations and dates of extreme precipitation events. The WDs used here differ very slightly in definition to the catalogue of Hunt et al. (2017) in that instead of filtering out tracks that do not pass through the box bound by $\left[20-36.5^{\circ} \mathrm{N}, 60-\right.$ $80^{\circ} \mathrm{E}$ ], we only filter out tracks whose geneses are west of $60^{\circ} \mathrm{E}$. This allows us to more accurately portray the broader picture, especially in summer, when the subtropical westerly jet in which the WDs are embedded is typically found north of $40^{\circ} \mathrm{N}$.

Fig. 7 shows the nearest TD and WD for the hundred strongest relative (left panel) and absolute (right panel) EPEs in summer (JJAS) and winter (DJFMA), in APHRODITE. Events with no nearby WD or TD are not shown. Since APHRODITE data represent daily accumulations, the WD or TD has been plotted at its most proximal location for the given day.

By drawing a naïve box $\left(20-40^{\circ} \mathrm{N}, 60-80^{\circ} \mathrm{E}\right)$ around the area of interest, and counting the number of systems in each category, we can estimate the impact these systems have on EPEs. For the winter relative EPEs, there were 7 TDs and 90 WDs; whereas for the summer relative EPEs, there were 36 TDs and 22 WDs. For the winter absolute EPEs, there were 4 TDs and 86 WDs; whereas in the summer case there were 27 TDs and 13 WDs. Of these eight counts, six - those not including the summer WDs - are significantly different from their respective climatologies at a $95 \%$ confidence level. Note that if we extend the eastern boundary of the box to $90^{\circ} \mathrm{E}$ to include the TDs at the southeast boundary of the monsoon trough, we recover about 75 TDs in each summer case, but this value is not significant compared to the climatology.

\footnotetext{
${ }^{4}$ The database of Hunt et al. (2016a) has here been expanded to include all seasons, with the tracking thresholds lowered to detect lows as well as depressions.
} 


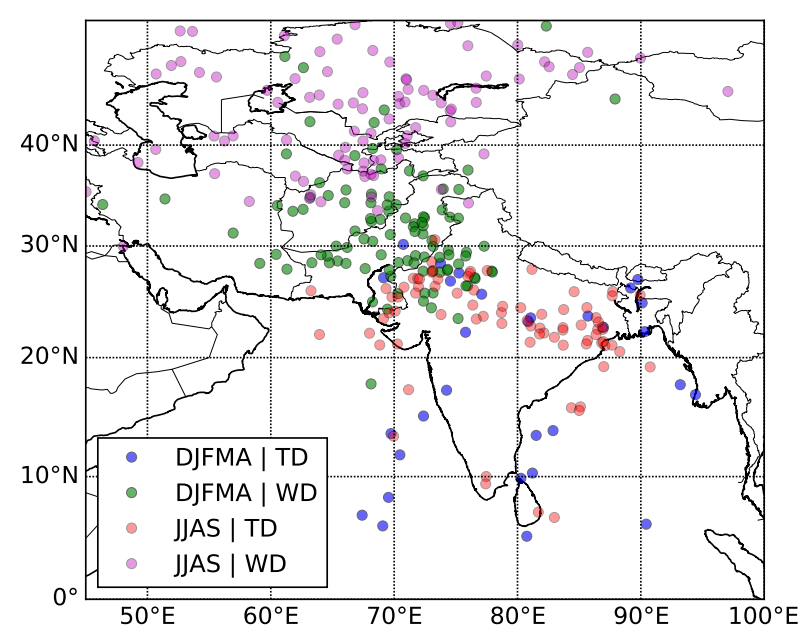

(a) Relative EPEs

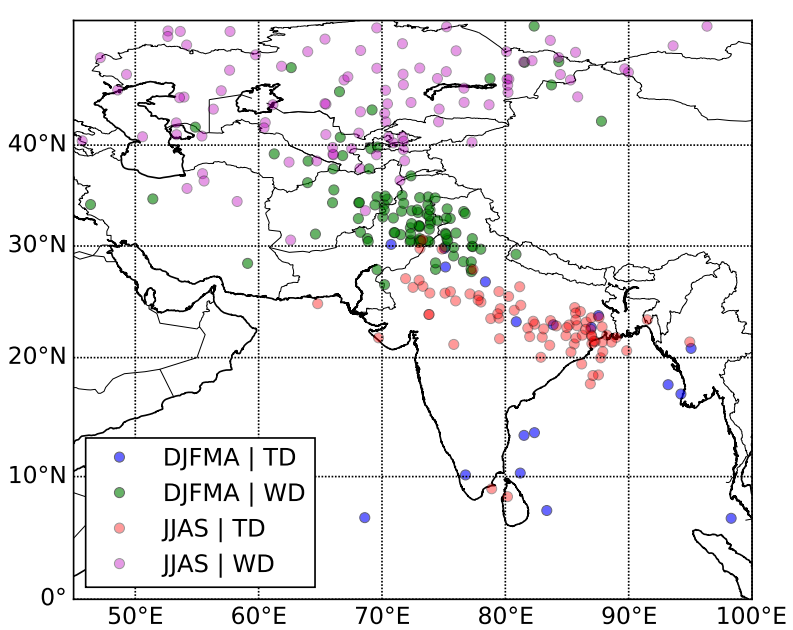

(b) Absolute EPEs

FIG. 7. Locations (if present) of the nearest tropical low (red, blue) and western disturbance (green, magenta) during the hundred strongest (a) relative and (b) absolute Hindustan EPEs for June-September (red, magenta) and December-April (blue, green). See text for definitions of the terms involved. Markers have nonzero transparency so that overlap can be seen.

As mentioned in the previous paragraph, some EPEs cannot be associated with disturbances in this box, for winter (summer) these total 14\% (64\%) and 11\% (48\%) for absolute and relative EPEs respectively. Climatologically, when rain is present in the Hindustan region, these values rise to $24 \%(63 \%)$, and increase again to $40 \%$ (79\%) when rain is not present in the Hindustan domain. We can conclude that, during the presence of such a disturbance, rain is more likely in either season, and furthermore that the likelihood of a relative EPE is increased in each season (though this holds only for winter in the case of absolute EPEs).

There are several conclusions to draw from this. Firstly, it is clear that for summer EPEs, especially relative ones, deeper penetration of TDs into the northwest can directly deliver the excess moisture necessary, as has been shown previously by e.g. Houze et al. (2011) and Rasmussen and Houze (2012). It is not necessarily sufficient, however, to have them at the head of the Bay of Bengal strengthening the monsoon trough. We cannot rule this out as a process, however - in the case of a TD being situated over east India or Bangladesh, low pressure systems here typically interact constructively with the monsoon trough to create active monsoon periods (Krishnamurthy and Ajayamohan, 2010), and vorticity over the Bay of Bengal has previously been shown to be positive correlated with the seasonal frequency of extreme rainfall events over India (Ajayamohan and Rao, 2008). During an active trough, moist southwesterlies strike the orography in north India and are capable of producing high rates of precipitation there (Rasmussen and Houze, 2012; Rasmussen et al., 2015; Houze et al., 2017). Secondly, there is a pronounced seasonal cycle derived from the climatology. WDs are markedly more common during winter EPEs as the subtropical jet is further south during this season (during winter months, the subtropical westerly jet is typically located directly above Pakistan and north India (Schiemann et al., 2009); during the summer it is typically in the extratropics); conversely TDs are more common during summer EPEs, the season in which they most frequently form. Thirdly, the mean centre of the WDs found in this analysis is found several hundred kilometres to the west - this suggests that the heavy precipitation is roughly collocated with the region of maximum ascent in WDs (Dimri and Chevuturi, 2016; Hunt et al., 2017).

\section{Moisture sources}

We have discussed the synoptic features that can be precursors to relative EPEs; however, for a complete picture, we must also consider how the moisture has arrived at its destination. Sourcing regional moisture remains a relatively open problem in meteorology, and a number of accepted methods are used - both Eulerian and Lagrangian, with phase changes (i.e. to ice, etc.) and without.

\section{a. Lagrangian approach}

Here, we use a simple Lagrangian method, discussed in Sec. 3, that does not keep track of phase changes. Such methods have been used previously (e.g. Stohl, 2001) to good effect. Throughout this section, we will consider the decomposition of columns split into forty "particles" equally spaced between 925 and $500 \mathrm{hPa}$, directly above the event of interest.

We shall start by looking at a handful of case studies, separated by season and precipitation. Firstly, examples 


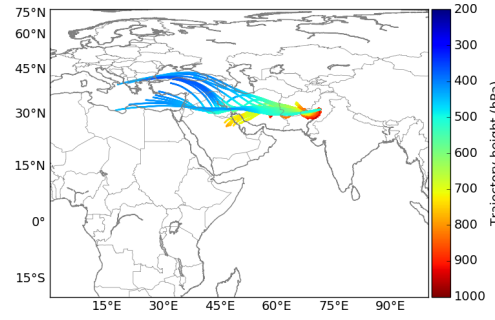

(a) extremely dry

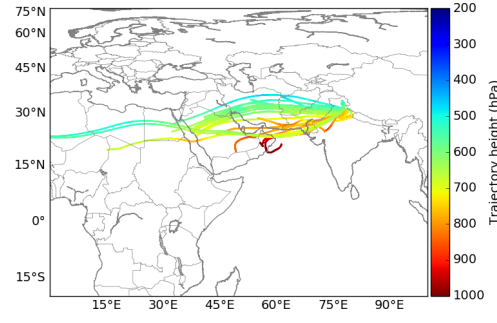

(b) median

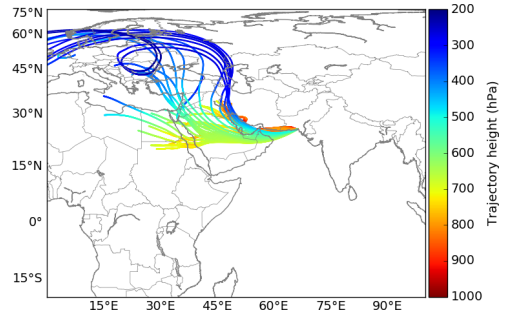

(c) extremely wet

FIG. 8. Forty parcel trajectories initialised in three selected winter case study columns, equally spaced between 925 and $500 \mathrm{hPa}$. The trajectories are computed backwards for five days according to the local, contemporaneous ERA-I winds. The columns are located at (a) 3 Dec $1990,71.5^{\circ} \mathrm{E}$, $31.5^{\circ} \mathrm{N}$ [extremely dry]; (b) $5 \mathrm{Feb} 1981,77.4^{\circ} \mathrm{E}, 33.9^{\circ} \mathrm{N}$ [median]; and (c) $4 \mathrm{Dec} 2006,66.4^{\circ} \mathrm{E}, 25.6^{\circ} \mathrm{N}$ [extremely wet]. Note that the colour scale differs between subfigures.

of backtracked trajectories for drought, median rainfall, and extreme rainfall events in winter are given in Fig. 8. The dry event was selected at random from the days in which no rainfall fell in the selected region, and the column has been taken from above a random pixel near the centre; the five-day back trajectories are given in Fig. 8(a). Here, there is a clear pattern: almost all of the trajectories originate from the upper troposphere and have subsided from in or near the subtropical westerly jet, the others from the dry lower-mid troposphere over the Arabian peninsula.

Taking the median value of all raining pixels across the ERA-I/APHRODITE overlap period (1979-2007) in the Hindustan box gives us the location and time of the case study median event, shown in Fig. 8(b). There are some strong similarities with the dry case, the presence of descent from the jet - this and the dry case both sit to the relative right of a jet exit, and the latter also to the relative left of a subsequent entrance - and some mid-/lowertropospheric air coming from over Arabia; however, there are also a handful of parcels coming from the boundary layer off the coast of Oman, which bring the moisture necessary for precipitation.

The pixel with the highest standardised precipitation index was selected as the wet case, and is shown in Fig. 8(c). This is rather different than the previous two cases, and is characterised by some boundary layer parcels from the vicinity of the Persian Gulf, but also a cyclonic disturbance bringing in northerlies and resulting in substantial mid-/lower tropospheric convergence. Corroboration with the database of Hunt et al. (2017) indicates that there was indeed a passing western disturbance during this event.

During the Indian summer monsoon (June-September), the climatological winds and humidity are very different from those prevailing during winter; therefore we repeat the above analysis for the summer months. The case-study selection method is different for the dry case only, as there is no summer day where there is no rain in the Hindustan box. The day with the area-average minimum was used instead, and is shown in Fig. 9(a). Some parcels originate from the boundary layer at the head of the Arabian
Sea, some from the boundary layer of the region itself, but the majority, as in the winter dry case, are brought in from upper-level westerlies. In all, and despite the different means of computation, the dry summer and dry winter cases are largely indistinguishable. Low-latitude Rossby waves such as these are thought to be associated with break phases of the South Asian monsoon (Krishnan et al., 2000).

The median case (Fig. 9(b)) looks quite different: while some parcels still originate from the (now weaker) upper-level westerlies, the majority are now monsoon-like southerlies that have spent considerable time in the boundary layer above the west Indian Ocean, with some evidence of a cyclone over Pakistan that pushes the monsoon winds from their usual westerly orientation to a southwesterly one; such a situation is fairly common during the break phase of the monsoon (Annamalai and Slingo, 2001), but it would be naïve to generalise from a casestudy.

In the wet case (Fig. 9(c)) there is a deep cyclone over the area of interest: all parcels originate from the local boundary layer, and beyond that from above the Arabian Sea or Bay of Bengal, indicating deep, moist ascent. Cross-referencing the date with the storm database of the India Meteorological Department confirms the presence of a severe cyclonic storm. These structures agree with previous studies (e.g. Vellore et al., 2016; Houze et al., 2017).

We now generalise this discussion to include $100 \mathrm{ex}-$ amples of each type of event; naturally this would create a very cluttered plot with many trajectories, so we will consider only the starts of the trajectories, i.e. the location after some specified duration of backtracking. To this end, we elect a duration of five days; this is sufficiently long that all the points are not crowded over each other, but not so long that we are likely to introduce significant errors from our integration. We again split this analysis on a seasonal basis, looking at winter-orientated events first. The members of the dry ensemble were selected in a similar fashion to the case-study: there are approximately 400 days in December-April 1979-2007 with no recorded 


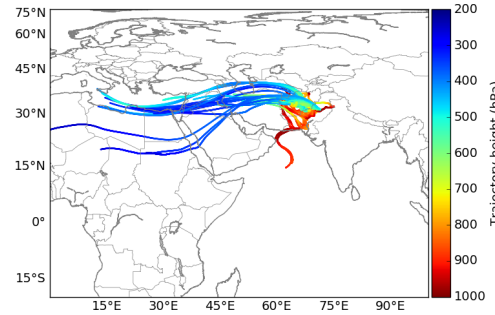

(a) extremely dry

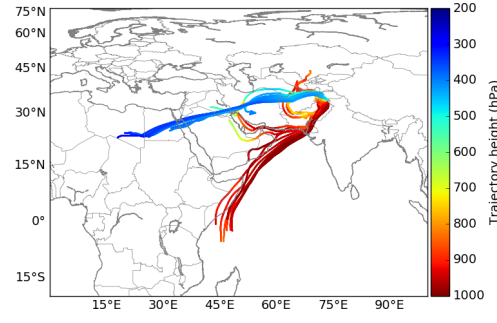

(b) median

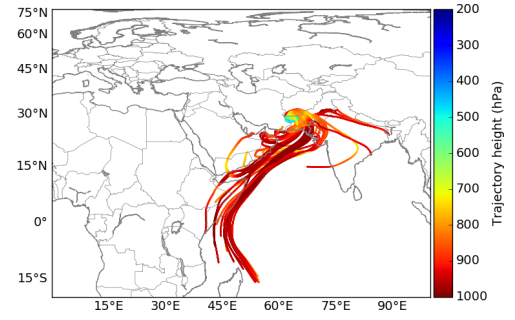

(c) extremely wet

FIG. 9. As in Fig. 8, but for selected summer case studies. Here, they are: (a) 11 Jun $1993,71.5^{\circ} \mathrm{E}, 31.5^{\circ} \mathrm{N}$ [extremely dry]; (b) $24 \mathrm{Jun} 1994$, $73.6^{\circ} \mathrm{E}, 34.1^{\circ} \mathrm{N}$ [median]; and (c) 28 Jun $2007,64.9^{\circ} \mathrm{E}, 29.1^{\circ} \mathrm{N}$ [extremely wet].

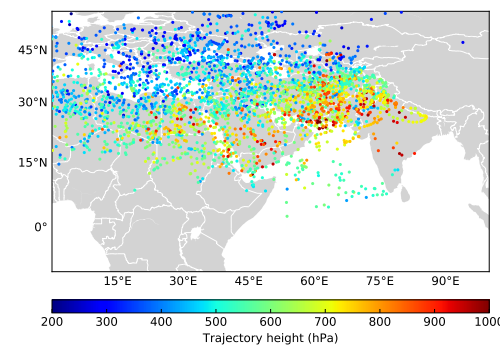

(a) extremely dry

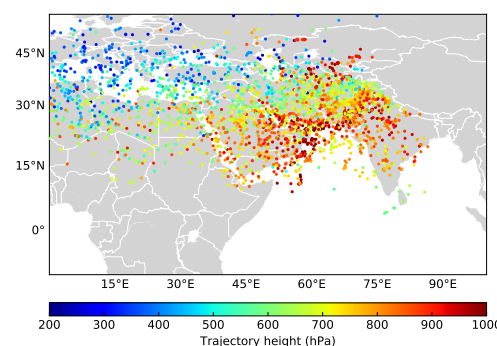

(b) median

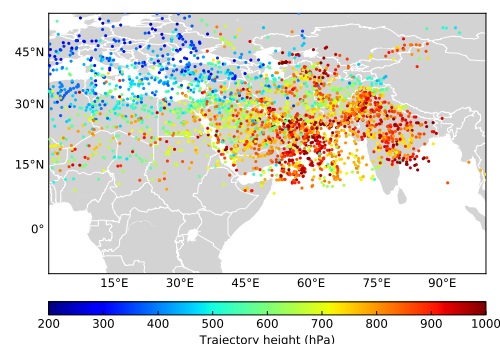

(c) extremely wet

FIG. 10. Locations of parcel origins from deconstructed columns above selected sets of 100 events computed from APHRODITE data. Columns are deconstructed into forty equally-spaced particles between 925 and $500 \mathrm{hPa}$; these particles are then advected backwards using three-dimensional winds from ERA-I for five days for the set of 100 events occurring December-April for which: (a) precipitation in the box [65-78 $\left.\mathrm{N}, 25-38^{\circ} \mathrm{E}\right]$ is zero (chosen at random); (b) precipitating pixels have values closest to the median precipitation for this period; and (c) standardised precipitation index is the highest.

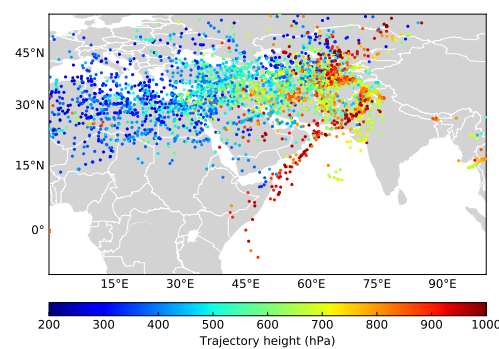

(a) extremely dry

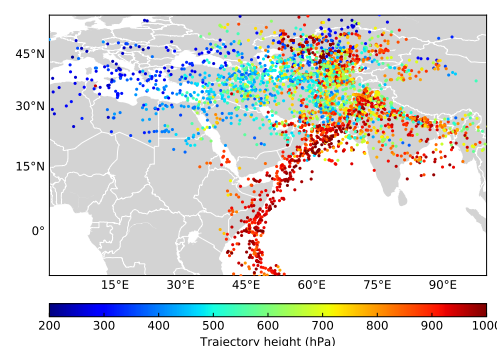

(b) median

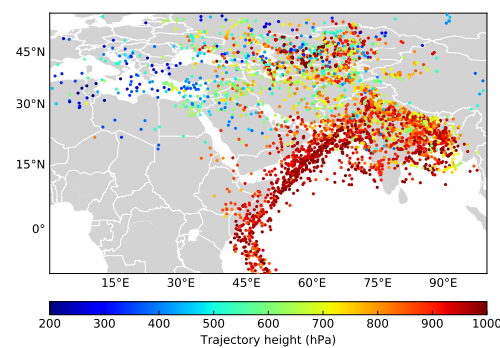

(c) extremely wet

FIG. 11. As Fig. 10, but for June-September, except for (a) in which the selected dates are those for which mean precipitation in the box [65-78 ${ }^{\circ}$, $\left.25-38^{\circ} \mathrm{E}\right]$ is lowest.

rainfall in APHRODITE in the Hindustan box. One hundred of these were chosen at random, and column coordinates were initiated at random within the box. As before, we split each of these hundred columns into forty equally spaced parcels between $925 \mathrm{hPa}$ and $500 \mathrm{hPa}$, and advect them backwards using local winds. Note that where these parcels are below the surface due to high orography, subsequent trajectory analysis is not performed.

The locations of the parcels five days prior to the composite dry event are shown in Fig. 10(a); as in the casestudy (Fig. 8(a)), one can see that the majority of parcels originate from upper-level westerlies, and five days prior are spread over much of Europe and north Africa. Only a very small minority of parcels can be found below $700 \mathrm{hPa}$, and these are confined relatively locally and typically over land.

The median ensemble comprises columns above the hundred pixels whose rainfall values are closest to the climatological median for the season (assuming non-zero rainfall), the locations of their constituent parcels five days prior are given in Fig. 10(b). There is a marked shift from the dry composite, fewer parcels seeming to come from the upper-troposphere over Europe, and more from the local lower-troposphere. Most notably these originate from 
over the Arabian peninsula and Arabian Sea, which is the most evident moisture source, as well as a small minority from near the surface of places reaching as far as the Red Sea and northeast India.

The wet ensemble comprises the hundred pixels collocated with the hundred strongest relative EPEs, whose locations five days prior are given in Fig. 10(c). The number of parcels in the upper-troposphere over Europe has increased slightly, but the local boundary-layer parcels are now more numerous and located firmly over the head of the Arabian Sea, rather than over the peninsula to its west. Further, there is a dramatic increase in parcels originating from over central India and the Bay of Bengal. This corroborates our earlier finding that synoptic-scale disturbances tend to be present during such events, as the prevailing climatological winds in this region are northwesterlies and so would push this moisture in the wrong direction.

As discussed before, the synoptic situation tends to be quite different in the South Asian summer compared to its winter, so we must split the analysis by season. Fig. 11(a) shows the locations of parcels from the dry June - September ensemble five days prior; the members of the ensemble are decided in a similar fashion to those in Fig. 10(a), except that we pick the days with the lowest mean in the Hindustan box, rather than randomly selecting days with no rainfall, as these are rather scarce in the summer. The location of the column is selected at random from the nonraining pixels in the box on the day of interest. The pattern bears some similarities with the winter dry ensemble (as was true with the case studies), though those parcels originating from the upper troposphere do so from over the Mediterranean rather than continental Europe. Furthermore, some parcels come from the boundary layer along the east coast of Africa, indicating that moisture will be present in these columns, but that it is typically not raining out.

The members of the median ensemble were computed in an identical manner to those in the winter equivalent, and their results are shown in Fig. 11(b). Here, a clear difference emerges: very few parcels seem to have recently been in the upper atmosphere at all, most now come from the boundary layer along the African coast, or are lowermid tropospheric parcels that have remained in situ.

The members of the wet ensemble were also computed in the same manner as for the winter equivalent, and their origins are shown in Fig. 11(c). Here, a majority of these parcels originate from near the surface of the Indian Ocean, along the Arabian and African coasts; with many of the rest coming from across northern and central India and the Bay of Bengal.

In summary, there is one major difference between the median and wet ensembles across both seasons, that is the large uptake of boundary layer parcels from north and central India, and the head of the Bay of Bengal.
This is indicative of influence from tropical disturbances, which may provide an additional source of moisture during events.

Now we know the origins of the air parcels comprising the atmospheric columns above EPEs, but we still do not know from where these parcels gather their moisture. Here, we select the starting points of backtrajectories thus: for each EPE, draw a box of side $300 \mathrm{~km}$ with the event at the centre, then look for the ten voxels of highest relative humidity in that box between 925 and $500 \mathrm{hPa}$ on the day of the event in ERA-Interim. These are then tracked back, as before, for five days, and coloured according to their specific humidity. This method is very similar to that used by Martius et al. (2013).

Fig. 12(a) shows these 1000 trajectories for the case of the hundred strongest relative EPEs for June - September. Whilst some of these parcels originate from over the Eurasian continent itself - apparently deriving their moisture from the Caspian Sea - the overwhelming majority of moisture is picked up from the Arabian Sea, as suspected (Sengupta and Sarkar, 2006; Levine and Turner, 2012). The overall pattern resembles that for composite extreme rainfall events over Nepal (Bohlinger et al., 2017) Some further parcels gain moisture from the Bay of Bengal, and there remains a positive northward gradient in specific humidity over the subcontinent itself, indicating that some additional moisture is further added to the incoming parcels by moisture flux convergence. Alternatively, this could be moisture recycling and re-evaporation from the moist/irrigated surface. In the winter case (Fig. 12(b)), there is no large scale monsoon flow to arrange the trajectories, as such the picture is a little more confusing. Again, a majority of the moisture seems to originate from the Arabian Sea, although other less local water sources play a part.

The composite for absolute EPEs in summer (see Fig. 13(a)) looks very similar to that for relative EPEs (Fig. 12(a)). There are two important differences, however: far fewer trajectories originate from the northwest, and the specific humidity gradient is now confined to the Himalayan foothills in the north where it is much steeper than before; here, we can conclude that orographic effects are a significant progenitor (which should come as no surprise given their locations in Fig. 2). Comparing the absolute EPE backtrajectories from winter (Fig. 13(b)) to their relative counterparts tells much the same story - there is less involvement from the northwest and the mountainous foothills towards the north of the peninsula play an increased role.

\section{b. Eulerian approach}

We have looked at the moisture paths from a Lagrangian point of view, but it leaves us with an incomplete picture: for example, is there local moisture flux convergence, or is 


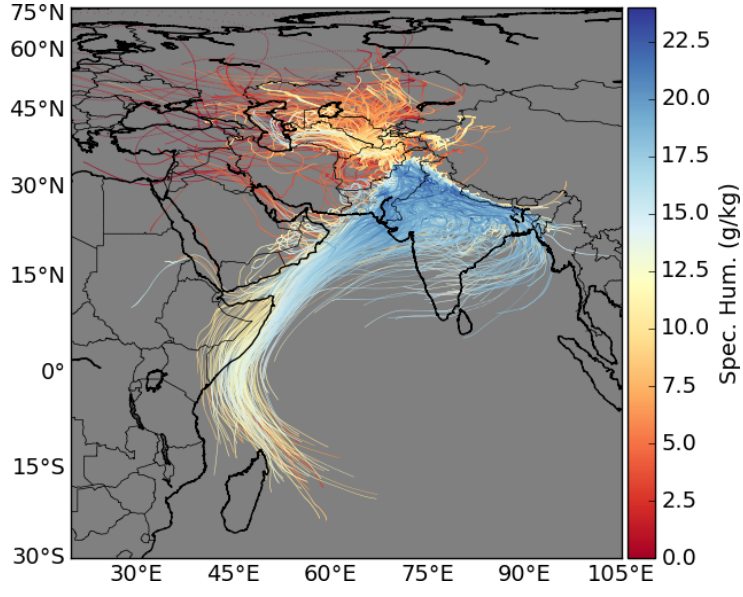

(a)

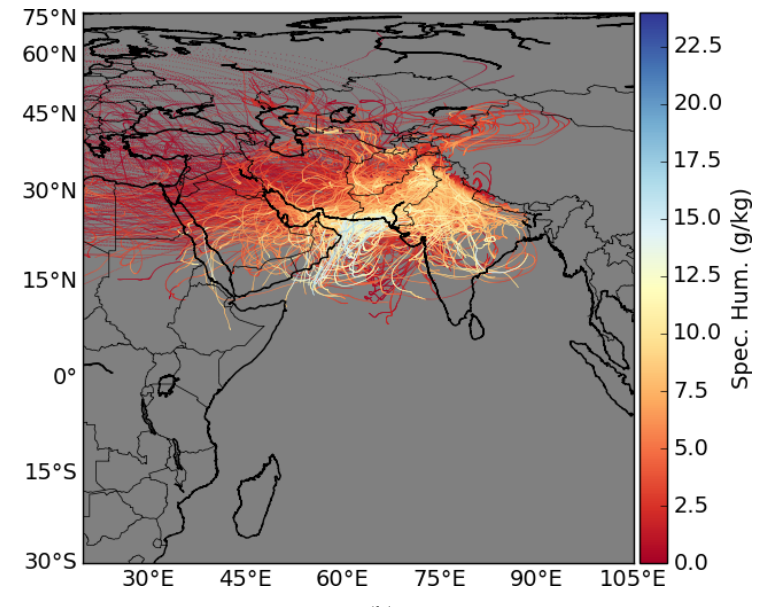

(b)

FIG. 12. 6-day back trajectories for each of the hundred strongest relative EPEs for (a) June - September and (b) December - April. For each event, we take a cuboid of side $300 \mathrm{~km}$ between $925 \mathrm{hPa}$ and $500 \mathrm{hPa}$ during the day of the EPE, finding the ten voxels therein with highest relative humidity. These are backtracked, giving 1000 trajectories in total.

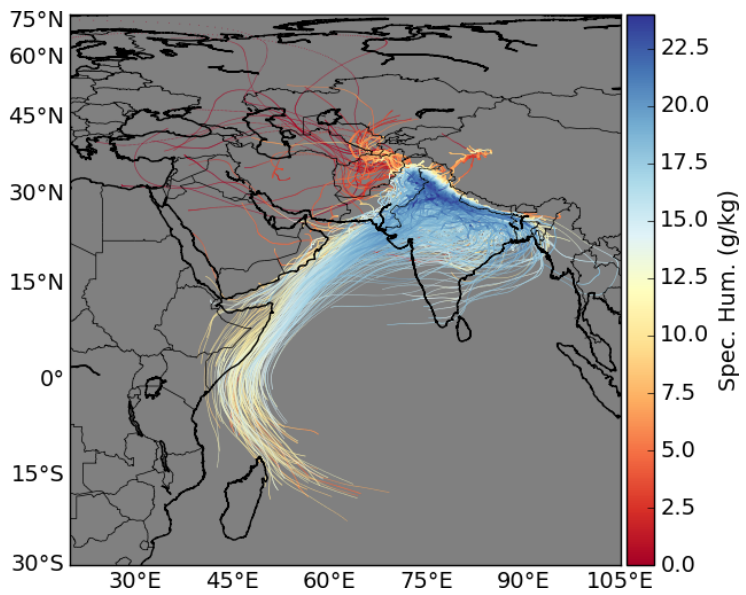

(a)

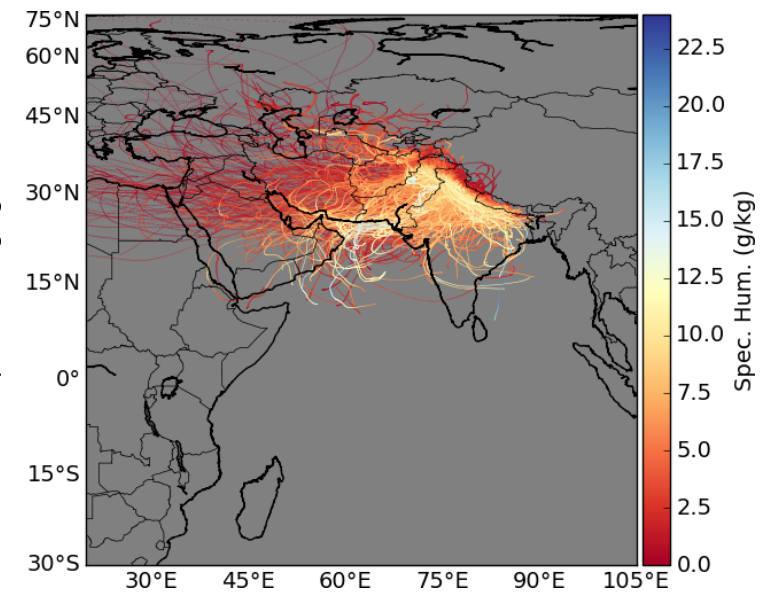

(b)

FIG. 13. As with Fig. 12, but for absolute EPEs.

the precipitation largely ascent-driven? By reverting to an Eulerian framework and considering the moisture fluxes themselves, we can investigate this directly. To this end, we are interested in the perturbations of these fields against a daily climatology, that is to say we define the moisture flux vector:

$$
(\mathbf{u} q)^{\prime}=\mathbf{u} q-\overline{\mathbf{u}} \bar{q}=\overline{\mathbf{u}} q^{\prime}+\mathbf{u}^{\prime} \bar{q}+\mathbf{u}^{\prime} q^{\prime}
$$

where the symbols have their usual meanings ( $\mathbf{u}$ is the vector wind field, $q$ is specific humidity, primed quantities are anomalies to daily climatologies, overbarred quantities are daily climatologies). Fig. 14 shows the horizontal component of anomalous moisture flux and its convergence, and the vertical component of anomalous moisture flux (all vertically integrated). The fluxes are composited for the hundred strongest relative EPEs in December-April 19792007, with a two-day lag (Fig. 14(a)) and on the day itself (Fig. 14(b)). The two-day lag shows that in the run-up to the composite event, a significant quantity of moisture is already being advected from the Arabian Sea over northwest India and north Pakistan, where some ascent takes place. On the day of the event, this moisture flux pattern becomes more cyclonic: the southwesterlies become westerlies over the Arabian Sea, developing into southerlies and even southeasterlies over the peninsula; further the magnitude of the flux grows significantly over the region of interest, both in the horizontal and the vertical. Together with the fact that there is little coherent anomalous convergence, this indicates that much of the precipitation during these winter extreme rainfall events is associated 


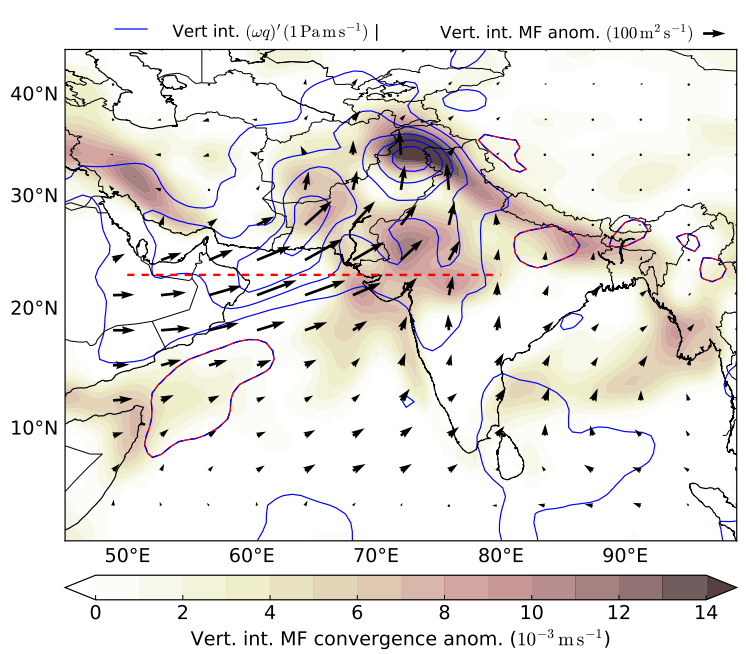

(a) day -2

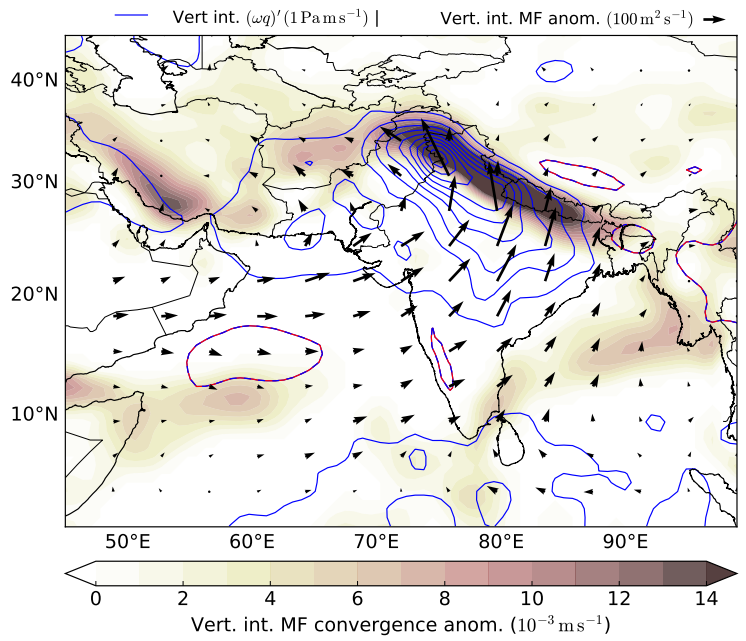

(b) day 0

FIG. 14. Moisture flux and convergence for the hundred most extreme relative events in December-April, presented for composites (a) with a two-day lag, and (b) on the day. Quivers give the direction and magnitude of vertically integrated horizontal moisture flux, line contours give the magnitude of the vertically integrated vertical moisture flux (intervals of $0.1 \mathrm{~Pa} \mathrm{~m} \mathrm{~s}^{-1}$ ); red indicates descent, blue indicates ascent. Solid contours give the vertically integrated moisture flux convergence $\left(10^{-1} \mathrm{~m} \mathrm{~s}^{-1}\right)$. All values are computed as anomalies against a daily climatology. The dashed red line in (a) is a plan view of the cross-section used in Fig. 15.

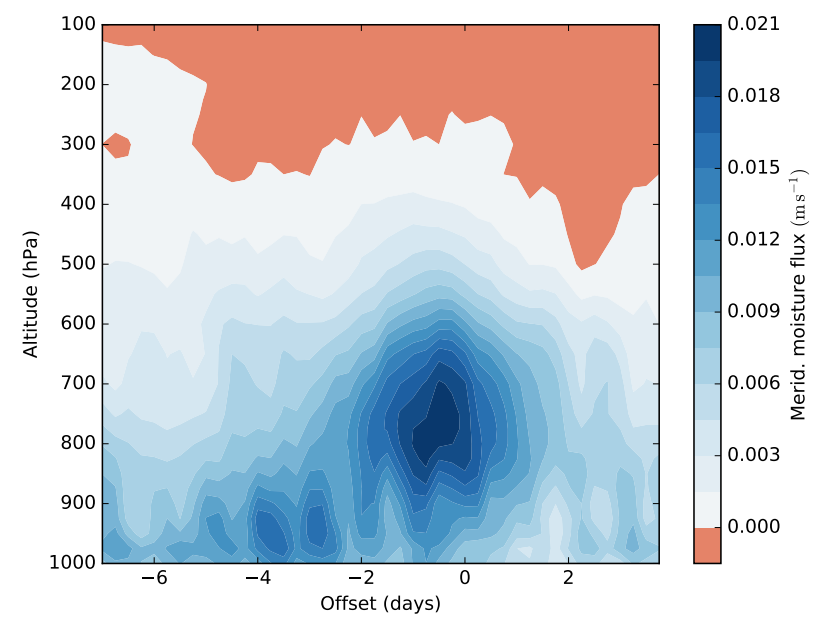

FIG. 15. Meridional moisture flux anomaly passing through $23^{\circ} \mathrm{N}$, between $50^{\circ} \mathrm{E}$ and $80^{\circ} \mathrm{E}$ (see Fig. 14(a)) as a function of lag time from the composite EPE. The composite EPE comprises the hundred strongest relative winter EPEs.

with ascent rather than convergence. Note that the shape of the vertical component of the vertically integrated moisture flux bears a strong resemblance to the composite total column water anomaly for the same period (Fig. 4(c)). Meridional transport is of clear importance, and we can follow its evolution more closely by looking at its mean vertical structure as a function of lag/lead for the composite winter EPE described above through the head of the Arabian Sea and central India.
The dashed red line in Fig. 14(a) runs along $23^{\circ} \mathrm{N}$, between $50^{\circ} \mathrm{E}$ and $80^{\circ} \mathrm{E}$, and is a representative southern border of our region of interest. Mean meridional moisture flux anomaly as a function of height and lag-time before/after the composite EPE is given in Fig. 15. There is a signal reaching back as far as a week in advance as boundary layer southerlies bring moisture over the coastline; this precedes an even greater transport in the lowertroposphere (between 800 and $700 \mathrm{hPa}$ ) throughout the day before. So, it seems as though the atmosphere is first primed through these southerlies moistening the boundary layer, before the much heavier transport at $\sim 750 \mathrm{hPa}$ throughout the preceding day eventually. Note that the diurnal cycle seen of the boundary layer is present in both the $v$ and $q$ components of Eq. 3 .

The same fields at the same offsets are given for the summer months June-September in Figs. 16(a) and 16(b) respectively. The most obvious difference between these figures and those from the winter-based composite is that the vertically integrated moisture flux vectors are much smaller in magnitude, and most of the action is confined to Punjab. One possible explanation is that during the winter, a precipitating storm has to obtain its moisture from a nearby water source, and its catchment area is thus the head of the Arabian Sea; however during the summer, much of the atmosphere is already highly moist as far as the Indo-Pakistani border, and only an extension of the north Indian southeasterlies is needed to provide the necessary water. In addition to this, there is also an area of high convergence in south Pakistan that was absent during the winter months, and is a further indicator that these 


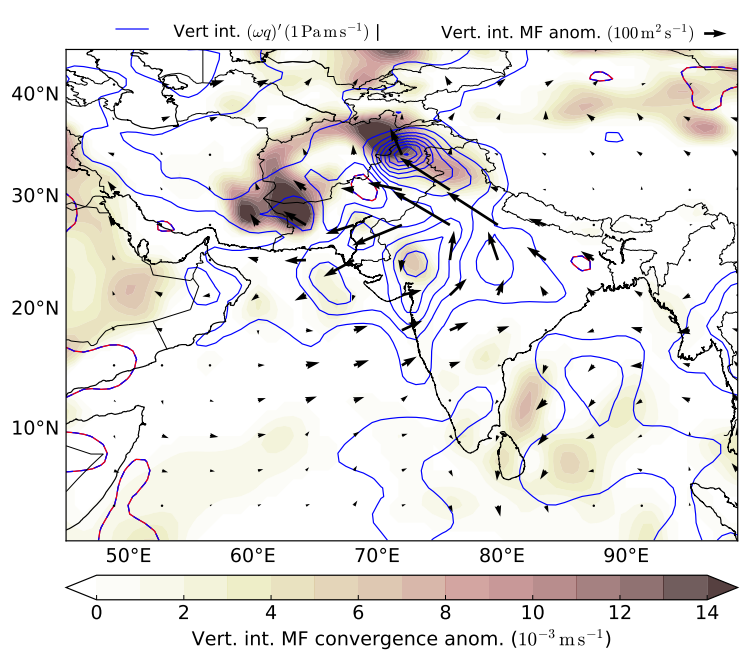

(a) day -2

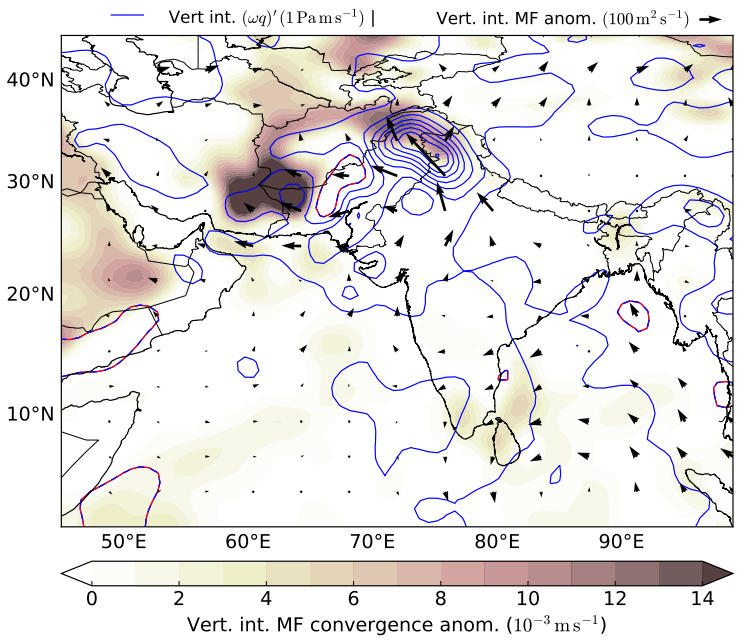

(b) day 0

FIG. 16. As in Fig. 14 but for June-September.

events can be caused by a brief northwestward extension of the Indian summer monsoon, a majority of whose own rainfall is typically caused by low-level moisture flux convergence (Ninomiya and Kobayashi, 1999).

\section{Conclusion}

Pakistan and northwest India contain substantial regions of both desert and upstream mountains, and as such are prone to sudden, heavy rainfall, or, extreme precipitation events (EPEs). Two classes of EPE were defined: absolute - for which events with the highest daily rainfall in each season were considered; and relative - for which events with the highest standardised precipitation index in each season were considered.

Previous studies (Lau and Kim, 2012; Martius et al., 2013; Houze et al., 2017) have highlighted the importance of mid- and upper-tropospheric dynamics as summer flood progenitors using case studies, and hinted at this being true for the general summer case. It has been demonstrated here that that is correct, and holds for winter floods too. For the case of extreme precipitation in winter, it has been shown (Pisharoty and Desai, 1956; Dimri, 2006; Dimri and Mohanty, 2009; Dubey et al., 2013) that western disturbances are associated with heavy rainfall; in this study, it was shown that nearly all winter EPEs could be linked to WDs, which can themselves be coupled with the upperatmosphere dynamics previously mentioned (Hunt et al., 2017).

Firstly, the large-scale anomalies over Eurasia during a composite of the top hundred relative EPEs for the summer (June-September) and winter (December-April) were examined. During winter there is strong evidence of an upper-level wave with planetary wavenumber 6 , seen in both the meridional wind - including intense anomalous southerlies over north Pakistan - and geopotential. Subsequent Hovmöller analysis showed that this wave has a group velocity of $38 \mathrm{~m} \mathrm{~s}^{-1}$ and phase velocity of $5 \mathrm{~m} \mathrm{~s}^{-1}$, which is comparable, but not identical, to the values predicted by simple barotropic theory. The presence of baroclinicity was confirmed by showing the poleward tilt of the associated geopotential anomaly. Vellore et al. (2014, 2016) showed that these anomalous upper-level southerlies also exist during the summer; but it is shown here that these patterns are weaker and less coherent than in the winter, and that there is some indication of a boundarylayer warm anomaly over western Russia, as demonstrated by Lau and Kim (2012) for the July 2010 floods.

Then, the role of circulating synoptic-scale systems was explored. Western disturbances, which are already known to be capable of triggering extreme rainfall events were present in almost all EPEs that were considered, although a significant minority, mostly during the summer, were too distant to have any meaningful effect on the local dynamics. In the winter, such systems can often be found directly over Pakistan and northern India, but they tend to retreat to the north during the summer - indicating a less direct relationship, if there is one at all, with precipitation in Hindustan. It is known that monsoon depression play a significant role in modulating summer rainfall over India (Dhar and Bhattacharya, 1973; Yoon and Chen, 2005), but their relationship with extreme rainfall events had not previously been quantified. In this study, it was demonstrated that some three-quarters of the hundred strongest relative EPEs in summer had a monsoon low pressure system nearby - either directly overhead, or towards the east end of the monsoon trough where they can enhance the monsoon circulation, though it is not clear whether the latter is an important process in EPE generation. Less than a 
third of equivalent winter events coexisted with a tropical low, and many of those were quite distant.

Finally, the origins of the moisture involved in winter and summer EPEs were investigated. Using a simple atmospheric column Lagrangian decomposition method, it was shown that both winter and summer dry events were largely dominated by upper-level subsidence and advection from the subtropical jet. Columns above "median" rainfall events in winter typically comprised a mix of local (including oceanic) boundary layer air, local mid-level air, and some descent from the westerly jet. Summer was much the same, although the boundary layer parcels came from a much more extended area along the African coast. For columns above the extreme precipitation events, though, the difference was stark. The winter EPE columns still comprised a relative mix of air, though much of it originated from the boundary layer above the head of the Arabian Sea. The summer EPE columns were comprised almost exclusively of boundary layer air, advected from either off the African coast by monsoonal southwesterlies, or from around the monsoon trough and Bay of Bengal, either brought there by climatological southeasterlies or a synoptic circulation; this composite of backtrajectories strongly resembles the case study done by Martius et al. (2013) for the July 2010 floods. A moisture flux analysis showed that the winter EPEs are largely ascent-driven (rather than convergence), whereas the summer EPEs tend to be a mix; and further that such events in winter are typically preceded by a moistening of the boundary layer that starts up to a week before.

The results presented here contribute to a better understanding of the processes that generate extreme rainfall in northwest India and Pakistan. Predominantly, these are modulated by monsoon low-pressure systems in the summer, and mid-latitude Rossby waves in the winter. It is hoped that in using these seasonal composites to diagnose the key mechanisms and synoptic situations that play a role in generating such devastating events, climate and numerical weather prediction models can be improved.

Acknowledgments. KMRH, AGT and LCS are funded by the JPI-Climate and Belmont Forum Climate Predictability and Inter-Regional Linkages Collaborative Research Action via NERC grant NE/P006795/1. The authors wish to thank the three anonymous reviewers who helped to improve the clarity, brevity, and robustness of this manuscript.

\section{APPENDIX}

\section{A1. Integrating the equations of motion on a sphere}

After appropriate discretisation, determining the path of a parcel being advected by winds on a spherical surface reduces to the problem of determining a new longitude and latitude given an initial coordinate, geodesic distance, and bearing. Here we shall state (but not derive) the formulae used.

Given a local wind vector comprising $u$ and $v$, the bearing, $\theta$, is given by:

$$
\theta=\tan ^{-1}\left(\frac{v}{u}\right)
$$

Then, the new latitude $\left(\phi_{f}\right)$ and longitude $\left(\lambda_{f}\right)$ are given by:

$$
\begin{gathered}
\phi_{f}=\sin ^{-1}\left(\cos \phi_{0} \cos \theta \sin \left(\frac{d}{R_{\oplus}}\right)+\sin \phi_{0} \cos \left(\frac{d}{R_{\oplus}}\right)\right) \\
\lambda_{f}=\lambda_{0}+\tan ^{-1}\left(\frac{\sin \theta \sin \left(\frac{d}{R_{\oplus}}\right) \cos \phi_{0}}{\cos \left(\frac{d}{R_{\oplus}}\right)-\sin \phi_{0} \sin \phi_{f}}\right), \quad \text { (A3) }
\end{gathered}
$$

where $R_{\oplus}$ is the radius of the Earth, and $d$ is the length of the geodesic.

\section{References}

Ajayamohan, R. S., and S. A. Rao, 2008: Indian Ocean dipole modulates the number of extreme rainfall events over India in a warming environment. J. Meteor. Soc. Japan, 86 (1), 245-252.

Annamalai, H., and J. M. Slingo, 2001: Active/break cycles: diagnosis of the intraseasonal variability of the Asian summer monsoon. Climate Dyn., 18 (1), 85-102.

Bohlinger, P., A. Sorteberg, and H. Sodemann, 2017: Synoptic conditions and moisture sources actuating extreme precipitation in nepal. J. Geophys. Res. Atmos., in Press.

Boos, W. R., and Z. Kuang, 2010: Dominant control of the South Asian monsoon by orographic insulation versus plateau heating. Nature, 463 (7278), 218-222, doi:10.1038/nature08707, URL http://dx.doi. org/10.1038/nature08707.

Coumou, D., V. Petoukhov, S. Rahmstorf, S. Petri, and H. J. Schellnhuber, 2014: Quasi-resonant circulation regimes and hemispheric synchronization of extreme weather in boreal summer. Proceedings of the National Academy of Sciences, 111 (34), 12 331-12 336.

Dee, D. P., and Coauthors, 2011: The ERA-Interim reanalysis: configuration and performance of the data assimilation system. Quart. J. Roy. Meteor. Soc., 137 (656), 553-597, doi:10.1002/qj.828, URL http://dx.doi.org/10.1002/qj.828.

Dhar, O. N., and B. K. Bhattacharya, 1973: Contribution of tropical disturbances to the water resources of Ganga basin. Vayu Mandal, 3, 76-79.

Dimri, A. P., 2006: Surface and upper air fields during extreme winter precipitation over the western himalayas. Pure Appl. Geophys., 163 (8), 1679-1698.

Dimri, A. P., and A. Chevuturi, 2016: Western disturbancesstructure. Western Disturbances-An Indian Meteorological Perspective, Springer, 1-26. 
Dimri, A. P., and U. C. Mohanty, 2009: Simulation of mesoscale features associated with intense western disturbances over western $\mathrm{Hi}$ malayas. Meteorological Applications, 16 (3), 289-308.

Dimri, A. P., D. Niyogi, A. P. Barros, J. Ridley, U. C. Mohanty, T. Yasunari, and D. R. Sikka, 2015: Western disturbances: a review. Rev. Geophys., 53 (2), 225-246.

Dubey, C. S., D. P. Shukla, A. S. Ningreichon, and A. L. Usham, 2013: Orographic control of the Kedarnath disaster. Current Science, 105 (11), 1474-1476.

Guo, H., S. Chen, A. Bao, J. Hu, A. S. Gebregiorgis, X. Xue, and $\mathrm{X}$. Zhang, 2015: Inter-comparison of high-resolution satellite precipitation products over Central Asia. Remote Sens., 7 (6), $7181-$ 7211.

Houze, R. A., L. A. McMurdie, K. L. Rasmussen, A. Kumar, and M. M. Chaplin, 2017: Multiscale aspects of the storm producing the June 2013 flooding in Uttarakhand, India. Mon. Wea. Rev., 145 (11), $4447-4466$

Houze, R. A., K. L. Rasmussen, S. Medina, S. R. Brodzik, and U. Romatschke, 2011: Anomalous atmospheric events leading to the summer 2010 floods in Pakistan. Bull. Amer. Meteor. Soc., 92 (3), 291298.

Hunt, K. M. R., A. G. Turner, P. M. Inness, D. E. Parker, and R. C. Levine, 2016a: On the structure and dynamics of Indian monsoon depressions. Mon. Wea. Rev, 144 (9), 33913416, doi:10.1175/MWR-D-15-0138.1, URL http://dx.doi.org/10. 1175/MWR-D-15-0138.1.

Hunt, K. M. R., A. G. Turner, and D. E. Parker, 2016b: The spatiotemporal structure of precipitation in Indian monsoon depressions. Quart. J. Roy. Meteor. Soc., doi:10.1002/qj.2901, URL http: //dx.doi.org/10.1002/qj.2901, in press.

Hunt, K. M. R., A. G. Turner, and L. C. Shaffrey, 2017: The evolution, seasonality, and impacts of western disturbances. Quart. J. Roy. Meteor. Soc., accepted.

Hurley, J. V., and W. R. Boos, 2015: A global climatology of monsoon low pressure systems. Quart. J. Roy. Meteor. Soc., 141, 1049-1064, doi:10.1002/qj.2447, URL http://dx.doi.org/10.1002/qj.2447.

Krishnamurthy, V., and R. S. Ajayamohan, 2010: Composite structure of monsoon low pressure systems and its relation to Indian rainfall. J. Climate, 23, 4285-4305, doi:10.1175/2010JCLI2953.1, URL http: //dx.doi.org/10.1175/2010JCLI2953.1.

Krishnamurti, T. N., M. K. Biswas, and D. V. B. Rao, 2008: Vertical extension of the Tibetan high of the Asian summer monsoon. Tellus A, 60 (5), 1038-1052.

Krishnan, R., C. Zhang, and M. Sugi, 2000: Dynamics of breaks in the Indian summer monsoon. J. Atmos. Sci., 57 (9), 1354-1372.

Lau, W. K. M., and K.-M. Kim, 2012: The 2010 Pakistan flood and Russian heat wave: Teleconnection of hydrometeorological extremes. $J$. Hydrometeor., 13 (1), 392-403.

Lekien, F., and J. Marsden, 2005: Tricubic interpolation in three dimensions. Journal of Numerical Methods and Engineering, 63, 455-471.

Levine, R. C., and A. G. Turner, 2012: Dependence of Indian monsoon rainfall on moisture fluxes across the Arabian Sea and the impact of coupled model sea surface temperature biases. Climate Dyn., 38, 2167-2190, doi:10.1007/s00382-011-1096-z.
Malik, N., B. Bookhage, N. Marwan, and J. Kurths, 2012: Analysis of spatial and temporal extreme monsoonal rainfall over South Asia using complex networks. Climate Dyn., 39 (3-4), 971-987.

Martius, O., and Coauthors, 2013: The role of upper-level dynamics and surface processes for the Pakistan flood of July 2010. Quart. J. Roy. Meteor. Soc., 139 (676), 1780-1797, doi:10.1002/qj.2082.

Ninomiya, K., and C. Kobayashi, 1999: Precipitation and moisture balance of the Asian summer monsoon in 1991. J. Meteor. Soc. Japan, 77 (1), 77-99.

Palazzi, E., J. Hardenberg, and A. Provenzale, 2013: Precipitation in the Hindu-Kush Karakoram Himalaya: Observations and future scenarios. J. Geophys. Res. Atmos., 118 (1), 85-100.

Palazzi, E., J. von Hardenberg, S. Terzago, and A. Provenzale, 2015: Precipitation in the Karakoram-Himalaya: a CMIP5 view. Climate Dyn., 45 (1-2), 21-45.

Petoukhov, V., S. Rahmstorf, S. Petri, and H. J. Schellnhuber, 2013: Quasiresonant amplification of planetary waves and recent Northern Hemisphere weather extremes. Proceedings of the National Academy of Sciences, 110 (14), 5336-5341.

Pisharoty, P. R., and B. N. Desai, 1956: Western disturbances and Indian weather. Indian J. Meteor. Geophys., 7, 333-338.

Prakash, S., and Coauthors, 2015: Seasonal intercomparison of observational rainfall datasets over india during the southwest monsoon season. Int. J. Climatol., 35 (9), 2326-2338.

Rasmussen, K. L., A. J. Hill, V. E. Toma, M. D. Zuluaga, P. J. Webster, and R. A. Houze, 2015: Multiscale analysis of three consecutive years of anomalous flooding in pakistan. Quart. J. Roy. Meteor. Soc., 141 (689), 1256-1276, doi:10.1002/qj.2433, URL http://dx.doi.org/ $10.1002 / \mathrm{qj} .2433$.

Rasmussen, K. L., and R. A. Houze, 2012: A flash-flooding storm at the steep edge of high terrain: disaster in the Himalayas. Bull. Amer. Meteor. Soc., 93 (11), 1713-1724.

Romatschke, U., and R. A. Houze, 2011: Characteristics of precipitating convective systems in the premonsoon season of South Asia. $J$. Hydrometeor., 12 (2), 157-180.

Romatschke, U., S. Medina, and R. A. Houze, 2010: Regional, seasonal, and diurnal variations of extreme convection in the South Asian region. J. Climate, 23 (2), 419-439.

Sayama, T., G. Ozawa, T. Kawakami, S. Nabesaka, and K. Fukami, 2012: Rainfall-runoff-inundation analysis of the 2010 Pakistan flood in the Kabul River basin. Hydrological Sciences Journal, 57 (2), 298-312.

Schiemann, R., D. Lüthi, and C. Schär, 2009: Seasonality and interannual variability of the westerly jet in the Tibetan Plateau region. $J$. Climate, 22 (11), 2940-2957.

Sengupta, S., and A. Sarkar, 2006: Stable isotope evidence of dual (Arabian sea and Bay of Bengal) vapour sources in monsoonal precipitation over north India. Earth and Planetary Science Letters, 250 (3), $511-521$

Sikka, D. R., 2006: A study on the monsoon low pressure systems over the Indian region and their relationship with drought and excess monsoon seasonal rainfall. Center for Ocean-Land-Atmosphere Studies, Center for the Application of Research on the Environment. 
Stohl, A., 2001: A 1-year Lagrangian "climatology" of airstreams in the Northern Hemisphere troposphere and lowermost stratosphere. J. Geophys. Res. Atmos., 106 (D7), 7263-7279.

Vellore, R. K., R. Krishnan, J. Pendharkar, A. D. Choudhury, and T. P. Sabin, 2014: On the anomalous precipitation enhancement over the himalayan foothills during monsoon breaks. Climate Dyn., 43 (7-8), 2009-2031.

Vellore, R. K., and Coauthors, 2016: Monsoon-extratropical circulation interactions in Himalayan extreme rainfall. Climate Dyn., 46 (1112), 3517-3546.

Webster, P. J., V. E. Toma, and H. M. Kim, 2011: Were the 2010 Pakistan floods predictable? Geophys. Res. Lett., 38 (4).

Yatagai, A., O. Arakawa, K. Kamiguchi, H. Kawamoto, M. I. Nodzu, and A. Hamada, 2009: A 44-year daily gridded precipitation dataset for Asia based on a dense network of rain gauges. Sola, 5, 137-140.

Yatagai, A., K. Kamiguchi, O. Arakawa, A. Hamada, N. Yasutomi, and A. Kitoh, 2012: APHRODITE: Constructing a long-term daily gridded precipitation dataset for Asia based on a dense network of rain gauges. Bull. Amer. Meteor. Soc., 93, 1401-1415, doi:10.1175/BAMS-D-11-00122.1, URL http://dx.doi.org/10.1175/ BAMS-D-11-00122.1.

Yoon, J.-H., and T.-C. Chen, 2005: Water vapor budget of the Indian monsoon depression. Tellus A, 57 (5), 770-782, doi:10. 1111/j.1600-0870.2005.00145.x, URL http://dx.doi.org/10.1111/j. 1600-0870.2005.00145.x. 